\title{
Nutrition and Muscle in Cirrhosis
}

\author{
Anil C. Anand \\ Indraprastha Apollo Hospital, New Delhi, India
}

\begin{abstract}
As the cirrhosis progresses, development of complication like ascites, hepatic encephalopathy, variceal bleeding, kidney dysfunction, and hepatocellular carcinoma signify increasing risk of short term mortality. Malnutrition and muscle wasting (sarcopenia) is yet other complications that negatively impact survival, quality of life, and response to stressors, such as infection and surgery in patients with cirrhosis. Conventionally, these are not routinely looked for, because nutritional assessment can be a difficult especially if there is associated fluid retention and/or obesity. Patients with cirrhosis may have a combination of loss of skeletal muscle and gain of adipose tissue, culminating in the condition of "sarcopenic obesity." Sarcopenia in cirrhotic patients has been associated with increased mortality, sepsis complications, hyperammonemia, overt hepatic encephalopathy, and increased length of stay after liver transplantation. Assessment of muscles with cross-sectional imaging studies has become an attractive index of nutritional status evaluation in cirrhosis, as sarcopenia, the major component of malnutrition, is primarily responsible for the adverse clinical consequences seen in patients with liver disease. Cirrhosis is a state of accelerated starvation, with increased gluconeogenesis that requires amino acid diversion from other metabolic functions. Protein homeostasis is disturbed in cirrhosis due to several factors such as hyperammonemia, hormonal, and cytokine abnormalities, physical inactivity and direct effects of ethanol and its metabolites. New approaches to manage sarcopenia are being evolved. Branched chain amino acid supplementation, Myostatin inhibitors, and mitochondrial protective agents are currently in various stages of evaluation in preclinical studies to prevent and reverse sarcopenia, in cirrhosis. ( $\mathrm{J}$ Clin Exp HePATOL 2017;7:340-357)
\end{abstract}

$\mathrm{T}$ he word malnutrition has different meanings for different people and is used in several contexts. Clinicians have been using this term to denote a phenotype characterized by loss of fat and muscles. ${ }^{1}$ WHO

Keywords: nutrition, cirrhosis

Received: 25 October 2017; Accepted: 2 November 2017; Available online: 8 November 2017

Address for correspondence: Anil C. Anand, Senior Consultant (Gastroenterology \& Hepatology), Indraprastha Apollo Hospital, New Delhi 110076, India.

E-mail: anilcanand@gmail.com

Abbreviations: aKG: alfa keto glutarate; Akt/PKB: serine/threonine-specific protein kinase B; AMPK: $5^{\prime}$ adenosine monophosphate-activated protein kinase; ASPEN: American Society of Parenteral and Enteral Nutrition; ATP: adenosine triphosphate; BIA: bio-electric impedance analysis; BMC: bone mineral content; BMI: body mass index; CT: computed tomography; DDLT: deceased donor liver transplantation; DRM: disease-related malnutrition; DXA: dual X-ray absorptiometry; ESPEN: European Society of Parenteral and Enteral Nutrition; FFI: Fried Frailty Index; FFM: fat free mass; FFMI: fat free mass index; FM: fat mass; HE: hepatic encephalopathy; LDLT: living donor liver transplant; LST: lean soft tissue; MAC: mid arm circumference; MAMC: mid arm muscle circumference; MELD: model for end-stage liver disease; MNA: Mini Nutritional Assessment; MRI: magnetic resonance imaging; mTORC1: mammalian target of rapamycin complex 1; NASH: non-alcoholic steatohepatitis; PCM: protein-calorie nalnutrition; (PG) SGA: patient-generated SGA; REE: resting energy expenditure; RQ: respiratory quotient (or RQ or respiratory coefficient); SGA: Subjective Global Assessment; SMI: Skeletal Muscle Index; SPPB: Short Physical Performance Battery; TIPS: trans jugular intrahepatic portocaval shunts; TNF: tumour necrosis factor; TSF: triceps skin fild thickness; WHO: World Health Organisation; YPA: total psoas area

https://doi.org/10.1016/j.jceh.2017.11.001 defines malnutrition as deficiencies, excesses or imbalances in a person's intake of energy and/or nutrients. ${ }^{2}$ The term nutrition broadly implies the food intake with a view to develop and maintain living body and extraction of energy for various metabolic activities including growth. Digestive system in general and liver in particular are involved in almost all the steps involved in these process including digestion, absorption, assimilation, and utilization of different micronutrients, hence it is not surprising to find malnutrition in liver disease. Moreover, imbalance among certain items consumed as food lead to liver diseases such alcoholic liver disease, and non-alcoholic fatty liver disease. Skeletal muscle abnormalities are an important and major component of malnutrition associated with cirrhosis and may adversely influence the course of illness in these patients. There is evidence to show that skeletal muscle abnormalities are related to poor outcome in cirrhosis as well as after liver transplantation. ${ }^{3,4}$ Several established prognostic models of cirrhosis such as ChildPugh $^{5}$ and D'Amico stage classification ${ }^{6}$ as well as and model for end-stage liver disease (MELD) scores ${ }^{7}$ do not include objective nutritional assessment. It may be due to the fact that objective assessment of nutrition is difficult due to ascites, edema, and/or associated obesity. ${ }^{8}$ Patients with cirrhosis often have progressive loss of muscle mass, strength and function, i.e. sarcopenia in addition to some metabolic muscle abnormalities. ${ }^{9,10}$ Concomitant loss of skeletal muscle mass and gain of adipose tissue leads to "sarcopenic obesity." "Recent advances in objective assessment of muscle mass, research into understanding 
of molecular basis of sarcopenia in cirrhosis, and discovery of novel targeted therapeutic options are promising to improve prognosis of cirrhotic patients. In this review the focus is mainly on the impact of cirrhosis on the nutrition, its consequences with special reference to muscles and its clinical, prognostic and therapeutic implications.

\section{DEFINING MALNUTRITION IN CIRRHOSIS}

Malnutrition is a common accompaniment in patients with cirrhosis of the liver and is also an important prognostic factor. Energy intake is commonly reduced in these patients due to several factor (Figure 1). ${ }^{12}$ There is a lot of ambiguity in the definition of malnutrition among adults in general and in patients with cirrhosis in particular. ${ }^{13}$ Malnutrition has a relatively clear definition in children and one talks of protein malnutrition (kwashiorkor) and combined protein and calorie malnutrition (marasmus). Since skeletal muscles play a central role in protein metabolism and storage, ${ }^{14,15}$ one may define clinical adult protein malnutrition as skeletal muscle loss. On the other hand, adipose tissue is the largest repository of calories, and therefore, adult energy malnutrition may be considered as a reduction in whole body fat mass. Clinical term 'cachexia' often conveys gross 'protein energy malnutrition' and by convention has been used for patients with muscle and fat loss. The term precachexia has also been defined on the basis of percentile values of the measured muscle and fat mass compared with controls. ${ }^{16}$ Loss of muscle mass also has been called 'sarcopenia' and loss of fat has been referred to as 'adipopenia'. While consensus definitions for such terms are being developed, ${ }^{17}$ their relevance to the complex metabolic and nutritional derangements in cirrhosis are yet to be evaluated. However, it is generally accepted that malnutrition in cirrhosis comprises reduced muscle mass, strength and function (sarcopenia), as well as loss of subcutaneous and visceral fat mass (adipopenia). ${ }^{1,18}$ Sarcopenia was originally described as loss of muscle mass related to aging, and that seen in cirrhosis would be termed as secondary sarcopenia. ${ }^{16,19}$ The term hepatic cachexia has been used to define a proportionate loss of both muscle and adipose tissue mass. Malnutrition in cirrhosis may also include loss or deficiency of several other nutrients such as vitamin $\mathrm{D}$ and zinc. Recent epidemic of obesity and fatty liverrelated cirrhosis has brought to our attention a unique entity of 'sarcopenic obesity' which is a disproportionate loss of skeletal muscle mass with preserved or increased visceral or subcutaneous adipose tissue mass. Thus, malnutrition in cirrhosis is an all encompassing term and includes sarcopenia, adipopenia, cachexia, precachexia, obesity, sarcopenic obesity, and micronutrient deficiencies. ${ }^{20}$ In view of foregoing, it is easy to understand why there is no unanimity in ideal method of diagnosis or objective assessment of malnutrition in cirrhosis.

\section{Malnutrition}

Basic diagnostic criteria for malnutrition in adults have been defined by ESPEN Consensus Statement, ${ }^{21}$ working group of the American Society of Parenteral and Enteral Nutrition (ASPEN) and by Academy of Nutrition and Dietetics (Academy). ${ }^{22}$ So, today malnutrition can be diagnosed if there is (a) reduced body mass index $(\mathrm{BMI})<18.5 \mathrm{~kg} / \mathrm{min}$ or underweight as defined by WHO; or (b) combined weight loss and reduced BMI (with age-dependent cut-offs); or (c) reduced gender-dependent

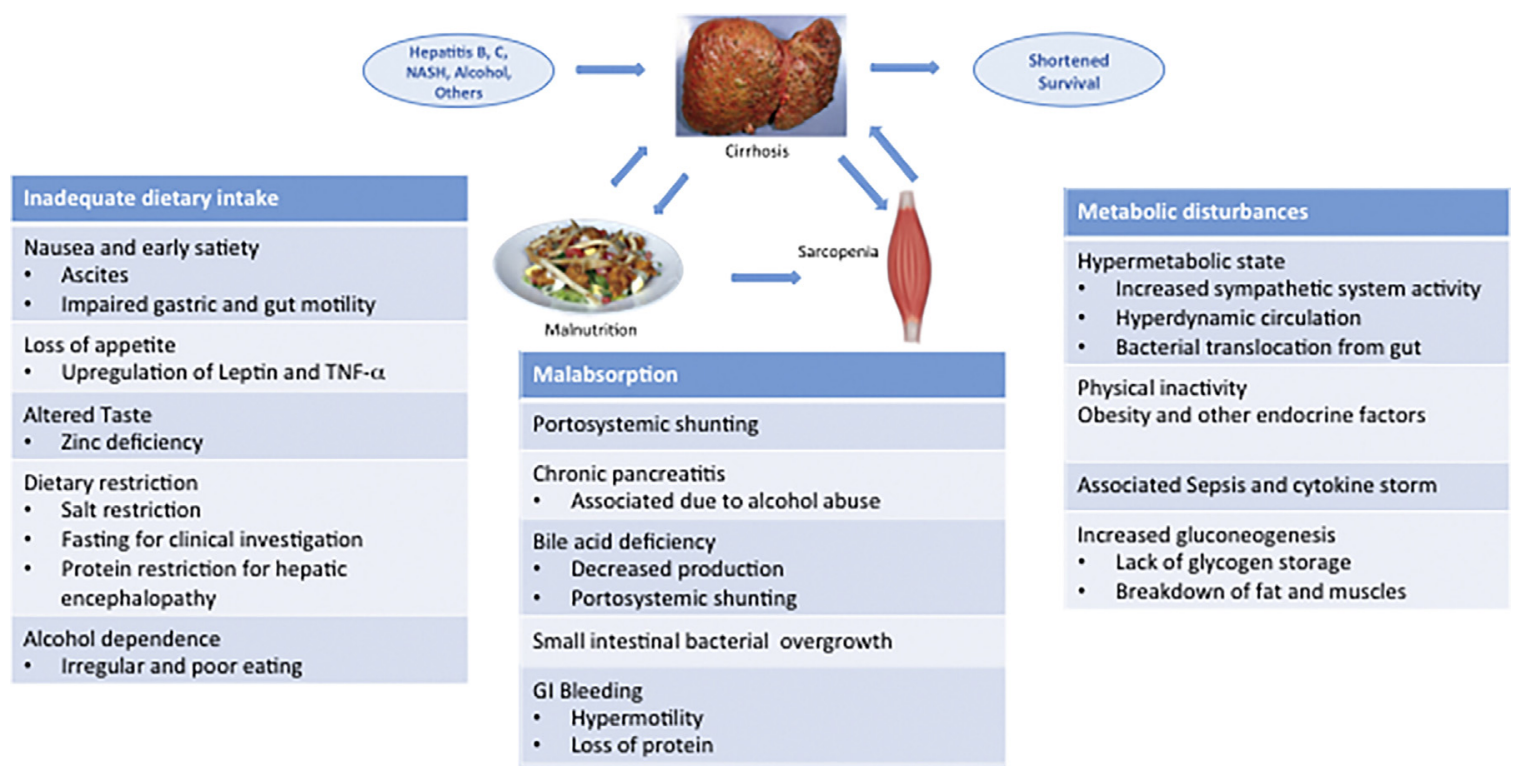

Figure 1 Cirrhosis caused by various etiologies leads to malnutrition and sarcopenia, which in turn enhance morbidity and mortality of cirrhosis. 
fat free mass index (FFMI); or (d) of a combination of six parameters defined (low energy intake, weight loss, loss of muscle mass, loss of subcutaneous fat, fluid accumulation, and hand grip strength) at least two are fulfilled. Malnutrition related to cirrhosis would possibly fall under sub-category of 'disease-related malnutrition (DRM) with inflammation' or 'chronic DRM with inflammation (synonym: cachexia). ${ }^{17}$

\section{Sarcopenia}

Sarcopenia is a syndrome characterized by the progressive and generalized loss of skeletal muscle mass, strength and function (performance) with a consequent risk of adverse outcomes. Sarcopenia primarily was described in relation to old age. Sarcopenia seen in cirrhosis would be classified as secondary sarcopenia that is one related to disease (cirrhosis), low physical activity (e.g. disuse) or due to poor nutrition (e.g. protein deficiency). ${ }^{20}$ Diagnostic criteria for sarcopenia in cirrhosis have not been firmly established to date. ${ }^{22}$ Currently, one may recommend an algorithm based approach on loss of muscle mass and strength and/or function. ${ }^{23}$ Muscle mass can be estimated by dual X-ray absorptiometry (DXA), bio-electric impedance analysis (BIA) or computed tomography (CT) scanning. For example, reduced muscle mass could be indicated by an appendicular skeletal muscle mass index $<7.26 \mathrm{~kg} / \mathrm{m}^{2}$ (men) and $<5.5 \mathrm{~kg} / \mathrm{m}^{2}$ (women). Reduced muscle function may be designated by reduced gait speed or failure of the chair standing tests (which tests lower extremities). Practical diagnostic cut-offs for gait speed are considered to be: $<0.8 \mathrm{~m} / \mathrm{s}$ or $<1.0 \mathrm{~m} / \mathrm{s}^{20,24}$ Reduced muscle strength may also be measured by handgrip strength; suggested cut-off points are $<20 \mathrm{~kg}$ for women and $<30 \mathrm{~kg}$ for men.

\section{Fraility}

Frailty, again, is a word commonly used in geriatrics and refers to state of vulnerability and non-resilience with limited reserve capacity in major organ systems. This leads to reduced capability to withstand stress such as trauma or disease and thus, frailty is a risk factor for dependence and disability. ${ }^{26}$ It involves two nutrition related components-weight loss and sarcopenia. ${ }^{25}$ Clinical phenotype of frailty can be defined by Fried Frailty Index (FFI), ${ }^{26}$ with patient meeting three out of five criteria: weight loss; exhaustion (fatigue); low physical activity; slowness (e.g. reduced gait speed); and weakness (e.g. low grip strength).

\section{Sarcopenic obesity}

Sarcopenic obesity is defined as obesity in combination with sarcopenia as is seen in patients with NASH, Diabetes type-2 and alcoholism. Here pathophysiology includes inflammation and/or inactivity induced muscle catabolism in obese patients. ${ }^{27}$ Currently, there are no commonly accepted diagnostic criteria for sarcopenic obesity beyond those for sarcopenia and obesity separately. ${ }^{26}$

\section{ASSESSMENT OF MALNUTRITION IN CIRRHOSIS}

Objective nutritional assessment in a cirrhotic patient would involve detailed history, physical examination and evaluation by predefined assessment tools like Subjective Global Assessment (SGA), ${ }^{28}$ Patient-Generated (PG) SGA and Mini Nutritional Assessment (MNA) and so on. Assessment of the nutritional status comprehends information on body weight, body height, BMI $\left(\mathrm{kg} / \mathrm{m}^{2}\right)$, body composition and biochemical indices. BMI has obvious limitations in patients with ascites and edema. Body composition analysis can be done by measuring fat free mass (FFM) and fat mass (FM) either by BIA or DXA-scan, but subject to the same limitations as weight measurements. Standard anthropometric measurements, such as mid-arm-circumference, calf-circumference or skinfold thickness are potential alternatives although subject to measurement variability. ${ }^{29}$ DXA gives information on FM, lean soft tissue (LST) and bone mineral content (BMC). The radiation dose of a single DEXA measurement is dependent on the device and the age of the patient, but is low and therefore the expected lifetime risk of fatal cancer is negligible. CT imaging is being increasingly used to evaluate muscle mass depletion. ${ }^{30} \mathrm{CT}$ scanning is often performed in patients with cirrhosis and same could be used for the evaluation of muscle mass. The fact that reference values are scarce for this technique will reduce its validity until such data are available for cirrhosis. Total psoas area (TPA)/cross sectional muscle are measured at lower level of L3/L4 vertebra correlates well with total body muscle mass. ${ }^{31,32}$ Skeletal Muscle Index (SMI) from single slice CT (2.6 milli-sieverts), appears to be more accurate than anthropometry or DEXA scanning and appear to be a practical method of assessment for clinicians. Reference values for cirrhotic population have not been worked out, but those extrapolated from Oncology population are being used, Sarcopenia is diagnosed at L3SMI $<52.4 \mathrm{~cm}^{2} / \mathrm{m}^{2}$ for males and $<38.5 \mathrm{~cm}^{2} / \mathrm{m}^{2}$ for females or if it is $<5$ th percentile of healthy males and females. ${ }^{9,33}$

Biochemical markers use in normal subjects are not suitable markers in cirrhotic patients. Levels of albumin ( $T_{1 / 2} 21$ days) and transthyretin/prealbumin ( $T_{1 / 2} 3$ days) are expected to be low in cirrhosis as they are synthesized in liver. Tests of physical function are crude, but nevertheless a relevant way to monitor nutritional care and therapy. Hand grip strength by a hand held dynamometer, gait speed or chair rise tests are fairly easy to undertake for the measurement of changes in muscle function sensitive to nutrition interventions. ${ }^{34}$ Composite functional scores, like the Short Physical Performance Battery (SPPB), ${ }^{35}$ De 
Table 1 Summary of Investigations Done for Assessment of Sarcopenia.

\begin{tabular}{|c|c|c|c|}
\hline Variable & Muscle mass & Muscle strength & Performance \\
\hline Research & $\begin{array}{l}\text { - Computed tomography (CT) } \\
\text { - Magnetic resonance imaging (MRI) } \\
\text { - Dual energy X-ray absorptiometry (DXA) } \\
\text { - Bioimpedance analysis (BIA) } \\
\text { - Total or partial body potassium per } \\
\text { fat-free soft tissue }\end{array}$ & $\begin{array}{l}\text { - Handgrip strength } \\
\text { - Knee flexion/extension } \\
\text { - Peak expiratory flow }\end{array}$ & $\begin{array}{l}\text { - Short Physical Performance Battery (SPPB) } \\
\text { - Usual gait speed } \\
\text { - Timed get-up-and-go test } \\
\text { - Stair climb power test }\end{array}$ \\
\hline Clinical practice & $\begin{array}{l}\text { - BIA } \\
\text { - DXA } \\
\text { - Anthropometry } \\
\text { - CT L3 SMI }\end{array}$ & $\begin{array}{l}\text { - Handgrip strength } \\
\text { - Frailty scores }\end{array}$ & $\begin{array}{l}\text { - SPPB } \\
\text { - Usual gait speed } \\
\text { - Get-up-and-go test }\end{array}$ \\
\hline
\end{tabular}

Modified from Ref. 20.

Morton Mobility Index ${ }^{36}$ or the Barthel Index ${ }^{37}$ have been used for research in geriatrics but may be cumbersome for routine clinical use (Table 1).

\section{PREVALENCE}

The association of protein-calorie malnutrition (PCM) with cirrhosis of any etiology is well-known and malnutrition may be nearly universal in end-stage liver disease. Prevalence has been reported from $34 \%$ to $82 \%$ in patients with alcoholic cirrhosis, based on anthropometric parameters. In patients with non-alcoholic cirrhosis, the prevalence of PCM ranges from $27 \%$ to $87 \%{ }^{38}$ A large published nutritional survey showed a $30 \%$ prevalence of PCM in male patients and $40 \%$ prevalence in female patients with cirrhosis. ${ }^{39}$ It must be realized that the prevalence of nutritional disorders is lower when malnutrition is diagnosed by anthropometric measures only. ${ }^{40,41} \mathrm{~A}$ high prevalence of malnutrition has been reported in patients with cirrhosis in studies in which visceral protein status and immunologic measures are included in the nutritional assessment. ${ }^{42-44}$ In one study, $81 \%$ of cirrhotic patients had decreased levels of visceral proteins, $59 \%$ had abnormal results on immunologic tests and 35\% had abnormal results on anthropometric tests. ${ }^{45}$ Prevalence of PCM increases as the severity of liver disease progresses, and has been reported from $20 \%$ in compensated liver cirrhosis to more than $80 \%$ in those patients with decompensate disease. ${ }^{44-48}$ A summary of some studies published about the prevalence of malnutrition using defined criteria is shown in Table $2 .{ }^{44,47,49-61}$ A summary of 18 studies, with a total of 3041 of subjects, measured malnutrition by a variety of methods, including SGA, mid arm muscle circumference (MAMC), triceps skin fold thickness (TSF), BIA, and clinical assessment. The prevalence of malnutrition ranges from $6.1 \%$ to $100.0 \%{ }^{13}$ Cause of cirrhosis included alcohol, viral, primary biliary, autoimmune, sclerosing cholangitis, and Wilson disease. Many of these patients have a hyper metabolic state. ${ }^{62}$ Patients with alcoholic liver disease are reported to have a greater incidence of malnutrition than those with non-alcoholic disease. ${ }^{63}$ Protein calorie malnutrition has been reported in $100 \%$ of those who receive liver transplant and malnutrition is an independent risk factor for morbidity and mortality in these patients. Frequently, patients with end stage hepatic failure not only have muscle wasting, but also decreased fat stores and overt cachexia. However, several patients will have fat-soluble vitamin deficiencies, anemia from iron, folate, and pyridoxine deficiency, altered cell-mediated immune function, and slow loss of muscle mass. ${ }^{44,64,65}$

Studies have shown that sarcopenia with specific cutoff values for muscle loss has been reported in $40-70 \%$ of cirrhotic patients. ${ }^{66}$ Sarcopenia worsens with severity of liver disease. ${ }^{13}$ The impact of severity of underlying liver disease as measured by the Child-Pugh scoring system showed that there is evidence of sarcopenia early in the course of the disease. These measures of sarcopenia become worse with progressive severity of liver disease. ${ }^{65,67}$ In the Pugh modification, the nutritional status was replaced by prothrombin time; the rationale for this was that the nutritional assessment used in the other versions had a significant subjective evaluation, whereas the prothrombin time in combination with serum albumin provides a more objective measure of long-term nutritional evaluation. ${ }^{68}$ Other measures of severity of liver disease, including the model for end-stage liver disease (MELD) score, have not been systematically assessed for their relation to the severity of sarcopenia, cachexia, or malnutrition. Several parameters, including grip strength, immune function, and serum albumin levels, have been used to describe variable prevalence. ${ }^{60,69}$ Cross-sectional imaging studies, including CT scan or magnetic resonance imaging (MRI), are currently considered gold standard investigation to quantify skeletal muscles as well as visceral and adipose tissue mass. They are objective, detailed, and reproducible tests for assessment of patients and identification of sarcopenia. ${ }^{70}$ One of the older tests, i.e. functional measures of muscle strength remains relevant and easy method to quantitate muscle function and thereby sarcopenia. ${ }^{71}$ 
Table 2 Malnutrition and Sarcopenia are Common in Patients of Cirrhosis. Summary of Some Studies That Show Prevalence of Malnutrition Along with Method Utilized for Diagnosis. BIABCM, Bioelectrical Impedance Analyzer Measured Body Cell Mass; SGA, Subjective Global Assessment; TBF, Total Body Fat; TSF, Triceps Skinfold Thickness.

\begin{tabular}{|c|c|c|c|c|}
\hline Year of publication & $\begin{array}{l}\text { Number of } \\
\text { subjects }\end{array}$ & Etiology & Diagnostic criteria & $\begin{array}{c}\text { Prevalence of } \\
\text { malnutrition (\%) }\end{array}$ \\
\hline 1984 xlv & 363 & Alcohol & Clinical diagnosis & 100 \\
\hline 1993 lii & 104 & $\begin{array}{l}\text { Alcohol, viral, primary biliary } \\
\text { and sclerosing cholangitis }\end{array}$ & $\begin{array}{l}\text { TSF }<\text { fifth percentile } \\
\text { MAMC }<\text { fifth percentile }\end{array}$ & $33<$ fifth percentile 43 \\
\hline 1996a liii & 60 & $\begin{array}{l}\text { Alcohol, viral, primary biliary } \\
\text { and autoimmune }\end{array}$ & $\begin{array}{l}\text { Anthropometric } \\
\text { BIA-BCM }\end{array}$ & 29 \\
\hline 1996b liv & 184 & All causes & Skinfold thickness & Child A, 8 Child B/C, 26 \\
\hline 1996c xlviii & 120 & $\begin{array}{l}\text { Alcohol } \\
\text { Viral }\end{array}$ & $\begin{array}{l}\text { Anthropometric } \\
\text { Visceral protein }\end{array}$ & $\begin{array}{l}34 \\
81\end{array}$ \\
\hline 1997 IV & 1015 & $\begin{array}{l}\text { Alcohol, viral, Primary biliary } \\
\text { and autoimmune }\end{array}$ & Clinical diagnosis & $33-60$ \\
\hline 2001a Ivi & 60 & $\begin{array}{l}\text { Alcohol } \\
\text { Viral }\end{array}$ & $\begin{array}{l}\text { Visceral protein } \\
\text { DTH } \\
\text { Ideal body weight }\end{array}$ & $\begin{array}{l}45 \\
22 \\
13.3\end{array}$ \\
\hline 2001b Ivii & 212 & $\begin{array}{l}\text { Alcohol } \\
\text { Viral }\end{array}$ & $\begin{array}{l}\text { TSF } \\
\text { MAMA }\end{array}$ & $\begin{array}{l}\text { Severe } 34 \\
\text { Moderate } 20\end{array}$ \\
\hline 2001c Iviii & 50 & $\begin{array}{l}\text { Viral, Primary biliary and } \\
\text { autoimmune }\end{array}$ & $\begin{array}{l}\text { BAI-BCM } \\
\text { TBF }\end{array}$ & $\begin{array}{l}\text { CTP A:71 } \\
\text { CTP C:81 }\end{array}$ \\
\hline 2003 lix & 77 & $\begin{array}{l}\text { Alcohol } \\
\text { Viral }\end{array}$ & $\begin{array}{l}\text { TSF } \\
\text { Albumin }\end{array}$ & 71 \\
\hline 2005a Ix & 79 & $\begin{array}{l}\text { Alcohol } \\
\text { Viral }\end{array}$ & $\begin{array}{l}\text { Body cell mass } \\
\text { TBF }\end{array}$ & 31.6 \\
\hline 2005b Ixi & 50 & All causes & $\begin{array}{l}\text { SGA } \\
\text { Prognostic nutritional state } \\
\text { Handgrip strength }\end{array}$ & $\begin{array}{l}28 \\
28 \\
63\end{array}$ \\
\hline 2007 Ixii & 268 & All causes & $\begin{array}{l}\text { Indirect calorimetry Grip } \\
\text { strength }\end{array}$ & $51 \%$ \\
\hline 2009 Ixiii & 114,703 & $\begin{array}{l}\text { Alcohol, viral, primary biliary } \\
\text { and autoimmune }\end{array}$ & Clinical diagnosis & 6.1 (1.9 control) \\
\hline 2010 Ixiv & 300 & All causes & Antropometric & 75 \\
\hline
\end{tabular}

\section{SIGNIFICANCE OF MALNUTRITION AND SARCOPENIA}

\section{Cirrhosis}

Several studies have indicated that malnutrition is an independent predictor of poor quality of life, hepatic decompensation (ascites, hepatic encephalopathy, and variceal bleeding), and mortality. ${ }^{56,60,72}$ In one study on 300 consecutive patients, it was shown that prevalence of overt HE was higher in patients with muscle depletion and decreased muscle strength, and venous blood ammonia levels also were higher with those who had sarcopenia. Protein malnutrition was found to have an odds ratio of 3.4 for predicting the presence of overt hepatic encephalopathy (HE). ${ }^{73}$ Another study reported that sarcopenia could predicted the presence of $\mathrm{HE}^{74}$ In yet another study on 84 patients, $29 \%$ with low hand grip strength had developed HE compared with none of the patients with normal grip strength. ${ }^{75}$ Even functional measures of frailty have been associated with lower survival in cirrhosis, independent of the MELD score. Each 100-m reduction in the $6 \mathrm{~min}$ walk test in one cohort of cirrhotics was independently associated with reduced survival (HR 0.48). ${ }^{76}$ Another study showed that each increase by one point in the Fried Frailty Index was associated with $45 \%$ increase in mortality, and each reduction by one point in the SPPB score correlated with a $19 \%$ increase in mortality. ${ }^{77}$ Reduced grip strength ( $\geq 2$ SD below the mean) has been associated with $20.7 \%$ one year mortality as compared to $0 \%$ mortality in those with higher readings $(P<0.05) .^{58}$

Frailty and sarcopenia predicts higher mortality among patients with cirrhosis who are liver transplant candidates. ${ }^{77,78}$ In a study on 112 patients with cirrhosis SMI was evaluated and it was shown that median survival of patients with low SMI was 19 vs. 34 months in those with a normal SMI. Sarcopenia was an independent risk factor for mortality when adjusted for ascites, encephalopathy, creatinine, bilirubin, and albumin (hazard ratio $2.18, P$ 5.006). ${ }^{79}$ Imaging of the psoas muscle area also has been 
used to prognosticate mortality in patients with cirrhosis, especially those undergoing liver transplantation. ${ }^{80,81}$ More recently a review of psoas muscle thickness suggested that a MELD-psoas score was better than the MELD score or MELD-Na score in prognosticating mortality. ${ }^{82}$ What leads to higher mortality is however not as evident though both increased risk of infection and encephalopathy may be contributory factors. ${ }^{83}$ Reduced muscle mass may also affect diaphragmatic action and lead to poor lung expansion especially after liver resection or liver transplantation and add to pulmonary infection complications. There is evidence to suggest that survival improve if sarcopenia can be reversed. In a study, reduction of portal pressure by TIPSS led to improvement in muscle mass in 41 of 57 patients. The 12-month mortality of patients with reversal of sarcopenia was $9.8 \%$ vs. $43.5 \%$ in those in whom sarcopenia persisted $(P=0.007) .{ }^{84}$

\section{Infection}

Sarcopenia in the elderly has been associated with increased infection risk $(\mathrm{RR}>2) .^{85}$ An association between sarcopenia and mortality in cirrhosis may be related to increased infection, especially when it is known that cirrhotics are particularly at high risk of sepsis-related death. ${ }^{86}$ A study mentioned earlier had suggested that increased mortality associated with sarcopenia was possibly due to an increase in sepsis-related deaths. ${ }^{79}$ Another study had also reported increased infection risk in those below the 25th percentile measured for mid-arm circumference as compared to those above $(32 \%$ vs. $8 \%$, $P=0.02) .{ }^{87}$ Infection risk was found to be fourfold higher in post liver-transplant patients with the lowest quartile of muscle mass compared with the highest quartile. ${ }^{88}$

\section{Miscellaneous}

Muscles play a central role in the protein metabolism of body and are major contributor of insulin-mediated glucose uptake. ${ }^{89}$ Sarcopenia therefore, reduces glucose uptake and increases insulin resistance, which facilitates progression of liver fibrosis and the development of hepatocellular carcinoma. ${ }^{90,91}$ Cytokines emanated by normal muscles (myokines) have a range of actions in mediation of inflammation. ${ }^{92}$ Sarcopenia may therefore potentiate the proinflammatory state of cirrhosis, a vicious cycle, may further reduce muscle mass. ${ }^{33}$ Muscle weakness necessarily limits capability to move around and adds to the feeling of fatigue. It can severely impact a person's quality of life. ${ }^{93}$ Weakness of muscles, altered metabolism may be responsible for muscle cramps which are common in cirrhosis and have been identified as a major factor affecting quality of life. ${ }^{94}$

\section{Post Liver Transplant}

Sarcopenia has been shown to be associated with poorer post-transplant outcomes, including increased length of stay and reduced survival. ${ }^{33}$ It has been shown that for each unit decrease in L3-SMI, there was 5\% increase in risk of death among male transplant recipients. And for each $10 \%$ increment in muscle mass was associated with a $9 \%$ shorter length of stay, and a $12 \%$ shorter ICU stay. ${ }^{95}$ Malnutrition and sarcopenia have also been shown to increase the risk of infection and the need for blood transfusion apart from longer hospital stays. ${ }^{96,97}$ Sarcopenic patients have been reported to have higher graft rejection and increased mortality, compared with nonsarcopenic patients. In a recent study, sarcopenia (defined by psoas muscle area) was associated with increased post transplant mortality. Total psoas area correlated poorly with MELD score, but it was strongly associated with posttransplant mortality with a hazard ratio of 3.7 for every $1000 \mathrm{~mm}^{2}$ reduction in psoas muscle area. ${ }^{98}$ In the setting of deceased donor liver transplantation (DDLT), during the waiting period, sarcopenia and nutrition may continue to worsen unless some active intervention is planned. While conventional complications of cirrhosis such as ascites, portal hypertension will be corrected after liver transplant, it appears that sarcopenia may not reverse or may even worsens in most patients after transplant. ${ }^{99,100}$ Post transplant mortality has been reported to be significantly higher in patients with ongoing muscle loss compared with patients who showed an increase in muscle mass after transplant. ${ }^{91}$ An interesting point is that postoperative worsening of sarcopenia was found to be more pronounced in men. ${ }^{101}$ Decreased measured skeletal muscle mass, muscle function and performance during cardiopulmonary testing, all have been associated with post-transplant mortality as with pre transplant mortality. ${ }^{102}$ Decreased muscle quality, defined as increased intramuscular adipose tissue, was additionally associated with higher post transplant mortality. ${ }^{81}$ This study of 200 living donor liver transplant (LDLT) recipients revealed that high intramuscular adipose content (odds ratio 3.9, 95\% confidence interval 2.0-7.8, $P<0.001$ ) and low psoas muscle index (odds ratio 3.6, 95\% confidence interval 1.9$7.2, P<0.001$ ) were independently predictive of mortality after liver transplantation.

\section{PATHOGENESIS}

There are several reasons for a patient of cirrhosis to be malnourished (Figure 1). Therefore, assessment of nutritional status is essential in planning treatment of patients with end-stage liver disease. ${ }^{103}$ Negative energy balance is largely due to poor intake. ${ }^{12}$ Patients with cirrhosis often consume a low caloric diet, due to several coexisting physical and cultural aberrations. Loss of appetite is related to the presence of circulating inflammatory cytokines such as tumor necrosis factor $\alpha($ TNF- $\alpha),{ }^{104}$ or alcohol-induced anorexia. Early satiety due to impaired gastric accommodation and impaired expansion capacity 
of the stomach secondary to the presence of clinically evident ascites often contribute to an inadequate nutrient intake. ${ }^{105,106}$ Abdominal pain, nausea and bloating are not uncommon in these patients and have been related to altered gut motility, and associated functional dyspepsia. ${ }^{107}$ Overall, increasing severity of gastrointestinal symptoms associated with recent weight loss and impaired health-related quality of life is present in most patients with cirrhosis and its extent is related to the severity of liver disease. ${ }^{108}$

There is additional component of impaired digestion and nutrient absorption due to portal hypertension, and it has been shown that controlling the pressure in the portal vein either by trans-jugular intrahepatic porto-caval shunts (TIPS) or medication could improve the patients' nutritional status. ${ }^{109}$ If cholestatic liver disease is present it adds to malabsorption of various nutrients, especially of fat-soluble vitamins such as A,D,E and $\mathrm{K}$, due to the reduced intraluminal bile salt concentrations. ${ }^{110}$ Apart from the established portal hypertensive enteropathy, other conditions such as altered intestinal flora and lesser synthesis and secretion of bile salts and pancreatic enzymes are also significant causes of malabsorption. Associated small intestinal bacterial overgrowth, coexistent small intestinal disease (inflammatory bowel disease, celiac sprue), pancreatic insufficiency, mucosal congestion and villus atrophy significantly contribute to the impaired absorption and utilization of nutrients. In this part of the world, due to some misconceptions many physicians continue to prescribe a low protein diet in order to 'prevent' hepatic encephalopathy leading to even poorer nutritional status. Multiple hospitalizations, drawing blood for repeated testing and asking patient to fast for imaging/ endoscopy or other tests also adds to protein and calorie malnutrition.

Resting energy expenditure (REE) is raised to the tune of $120 \%$ of the expected value in more than half the patients with cirrhosis. ${ }^{111}$ Elevated pro-inflammatory and anti-inflammatory cytokine levels point to a cytokine-driven hyper-metabolism in cirrhosis. ${ }^{112}$ In addition, hyperdynamic circulation leads to a systematic vasodilatation and to an expanded intravascular blood volume and stimulation of sympathetic nervous system. As a direct effect, a higher stroke output and therefore a greater use of macro- and micronutrients is also commonly associated and leads to relative deficiency of these nutrients. ${ }^{113,114}$

In cirrhosis, as the liver fibrosis progresses, there is increasing levels of inflammatory state. ${ }^{11,115}$ Gut barrier function is compromised due to portal hypertension and dysbiosis in cirrhotics and leads to translocation bacterial products which are recognized as pathogen associated molecular patterns (PAMPs) by immune cells leading to activation of pro-inflammatory state. ${ }^{116,117}$ Other overt infections such as spontaneous bacterial peritonitis, worsening hepatic encephalopathy or the presence of fever of unknown origin, also add to the increased REE. In these circumstances, patients may experience deterioration in their general health and nutritional status. Add to this a state of accelerated starvation seen in cirrhosis. ${ }^{118,119}$ During overnight fast in healthy subjects, a switch to gluconeogenesis from amino acids derived from muscle proteins is commonly seen. ${ }^{120}$ Cirrhotic patients have poor hepatic glycogen reserves due to the impaired synthetic capacity of hepatic cells, and hence an overnight fast in these patients is equivalent to nearly $72 \mathrm{~h}$ fast in healthy persons. ${ }^{118,119,121}$ As a result metabolism shifts to fatty acids as a dominant substrate for oxidation in human patients with cirrhosis. Some tissues dependent on glucose will need neoglucogenesis from amino acids as fatty acids cannot be used for this process. This leads to mobilization of amino acids from the skeletal muscles so that the adequate amount of glucose can be produced. Repeated and frequent fasting results in recurrent proteolysis resulting in muscle loss in human cirrhotic patients. ${ }^{122}$ Several iatrogenic measures result in loss of protein and minerals in cirrhotics. Multiple large volume paracentesis, use of diuretics and lactulose as prebiotic are some such measures. Occult or overt blood loss from esophageal and gastric varices and ulcerations/portal enteropathy add to the protein loss (Figure 2). ${ }^{123}$

Deficiency in vitamins and other trace minerals is not uncommon in liver cirrhosis. Fat soluble vitamins may be poorly absorbed due to cholestasis and portal hypertensive enteropathy leading to vitamin $\mathrm{A}, \mathrm{K}$ and vitamin $\mathrm{D}$ deficiency with associated coagulopathy and hepatic osteodystrophy. ${ }^{124,125}$ In addition, osteoporosis as a result of calcium loss and malabsorption, deficiencies in folate, riboflavin, nicotinamide, pantothenic acid, pyroxidine, vitamin $B_{12}$ and thiamine, decreased levels of zinc, magnesium, sodium and phosphorus have also been described. ${ }^{126}$ Zinc deficiency alters appetite and taste, impairs wound healing, immune reaction, and protein metabolism. ${ }^{127,128}$

\section{SKELETAL MUSCLE LOSS AND SARCOPENIA}

Sarcopenia has special significance in cirrhosis as outlined above, and is made worse by negative energy balance as well as obesity. A fat rich diet associated to physical inactivity often leads to of increased fat deposits and insulin resistance, which are also able to produce proinflammatory adipokines, and catabolic metabolism in muscle mass (sarcopenic obesity). ${ }^{129-131}$ Sarcopenia is common is cirrhosis with prevalence ranging $40-70 \%$ often related to the severity of liver disease. ${ }^{53}$ Skeletal muscle mass is maintained by a delicately balanced 


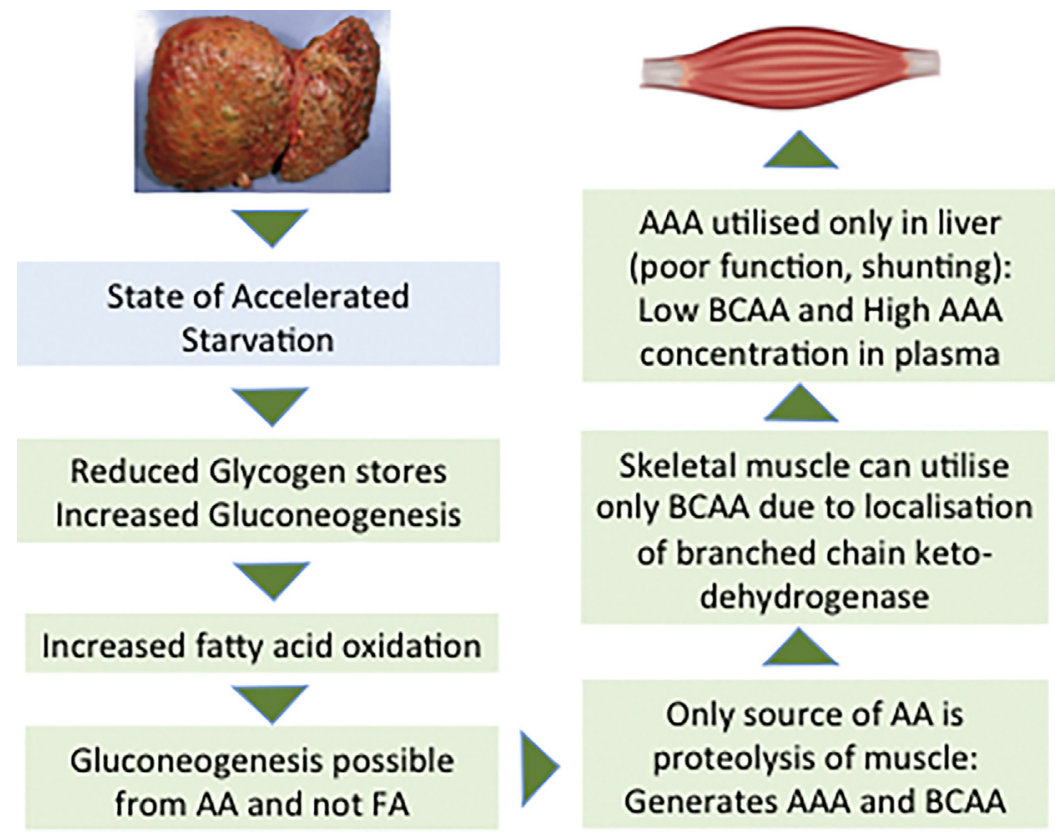

Figure 2 Cirrhosis is a state of accelerated starvation and neoglucogenesis has to proceed from amino acids. The figure explains why BCAA administration may be helpful in patients with cirrhosis. BCAA: branched chain amonoacids, AAA: aromatic aminoacids.

relationship between protein synthesis, proteolysis, and satellite cells in muscles, which are the stem cells responsible for skeletal muscle regeneration. ${ }^{3}$ Protein synthesis in health is biochemically up regulated by mammalian target of rapamycin complex 1 (mTORC1), which spurs on ribosomal translation of capped messenger RNA. ${ }^{132}$ It is counter balanced by an inhibitor-myostatin (a transforming growth factor $\beta$ superfamily member) and two proteolytic pathways, i.e. the ubiquitin proteasome and autophagy pathways. ${ }^{133,134}$ Common mechanisms affecting this balance and leading to sarcopenia in cirrhosis are outlined in Figure 3.

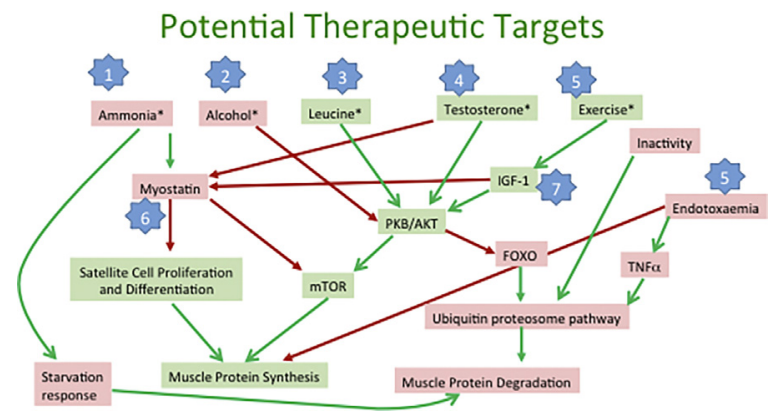

Figure 3 Overall balance of muscle protein synthesis and degradation and factors that control such a balance. Green boxes contain promotors of muscle protein synthesis, pink boxes contaon factors that promote muscle degradation. Green arrows: facilitatory pathways, red arrows: inhibitory pathways. Blue stars indicate potential therapeutic targets for reversing sarcopenia in cirrhosis. Numbers 1-7 indicate potential targets to reverse sarcopenia as described in text. IGF-1, insulin-like growth factor 1; PKB/AKT, protein kinase B; mTOR, mammalian target of rapamycin; FOXO, forkhead box transcription factor.

\section{Hyperammonemia}

Hyperammonemia is a common abnormality in cirrhosis due to failure of liver urea cycle, and leads to increased ammonia uptake by the skeletal muscle and elevated muscle ammonia concentrations. ${ }^{135,136}$ Ammonia imbalances skeletal muscle protein metabolism by impaired muscle protein synthesis and increased muscle autophagy. ${ }^{137}$ A lot of recent work has focused on elucidating pathogenesis of sarcopenia caused by hyperammonemia. ${ }^{138}$ In vitro experiments have shown that hyperammonemia-mediated activation of p65-NF-kB (an intracellular protein complex containing nuclear factor kappa-light-chain-enhancer of activated $\mathrm{B}$ cells) is associated with increased expression of myostatin, a TGF $\beta$ superfamily member ${ }^{137,139}$ which has been observed bay many workers in relation to cirrhosis. ${ }^{140}$ Myostatin is an inhibitor of protein synthesis and activates the ubiquitin proteasome and autophagy mediated proteolysis. ${ }^{134,141}$ Ammonia may also cause mitochondrial dysfunction and generation of reactive oxygen species as have been reported in the neural tissue. ${ }^{142,143}$ In cirrhotic patients, the skeletal muscle functions as a metabolic partner for the liver. Due to impaired urea-genesis and decreased hepatic ammonia disposal, skeletal muscle ammonia concentrations are much higher, potentially favoring protein catabolism or loss of critical Kreb's cycle intermediate, aKG. ${ }^{137,144}$ This results in lower flux of the Kreb's cycle, impaired mitochondrial function and decreased adenosine triphosphate (ATP) synthesis. Low ATP concentrations lead to reduced protein synthesis as latter is an energy intensive activity. 
Hyperammonemia also inhibits oxo-dehydrogenases such as pyruvate dehydrogenase, (essential for generating acetyl coenzyme A), and aKG dehydrogenase (for conversion to succinyl coenzyme A). Ongoing mitochondrial dysfunction, generation of reactive oxygen species, and impaired bioenergetics in the skeletal muscle, all may contribute to impaired protein synthesis and activate a metabolic, adaptive response, autophagy. Decreased cellular ATP is associated with activation of the cellular energy sensor, $5^{\prime}$ adenosine monophosphate-activated protein kinase (AMPK) and impaired mTORC1 signaling. ${ }^{138}$ In addition, use of proteins as a source of neo-glucogenesis leads to generation of aromatic and branched chain amino acids (AAA and BCAA). Muscles can only utilize BCAA due to localization of branched chain keto-dehydrogenease. It results in low circulating BCAA with skeletal muscle concentrations of BCAA expected to be further decreased in the muscle of cirrhotics. Reduced cellular amino acid concentrations activate adaptive responses that include increased skeletal muscle autophagy which has been reported in cirrhosis. Supplementation of leucine and some other amino-acids may correct impaired mTORC1 signaling in patients with cirrhosis as well as in vitro studies. ${ }^{145,146}$ Hyperammonemia leads to excessive glutamine synthesis in the muscle and its transport into the circulation. Therefore, in the face of low muscle mass, non-hepatic disposal of ammonia is likely to be impaired which may add to its CNS effects. No wonder, as has been noted above, encephalopathy is more frequent in sarcopenic than non-sarcopenic cirrhotics. ${ }^{75,140}$

\section{Pattern of Energy Expenditure in Liver Disease}

Several studies have shown that cirrhosis is a state of accelerated starvation. ${ }^{118,121}$ In the fed state, carbohydrates and glucose are the primary substrate for oxidation and energy generation and yield an RQ close to one. ${ }^{147} \mathrm{At}$ this time protein synthesis is the main activity in the muscles. In an overnight fasted state, there is gradual transition to use fatty acids as main substrate for oxidation (with a reduced RQ) in patients with cirrhosis. ${ }^{122}$ While many tissues can survive with fatty acids oxidation, some tissues will necessarily require glucose thereby increasing the need for gluconeogenesis. Fatty acids can not be used for gluconeogenesis, therefore amino acids are broken down for this activity. ${ }^{148,149}$ Repeated and frequent fasting thus, results in progressive loss of protein. This, when combined with anabolic resistance seen in cirrhosis results in incomplete restoration of protein stores culminating in muscle loss in human cirrhotic patients. $^{122}$

\section{Alcohol}

There are reports to show increased autophagy in the muscle of patients with alcoholic liver disease. ${ }^{133,150}$
Acetaldehyde, a cytotoxic ethanol metabolite, impairs ornithine transcarbamylase, the critical rate-limiting enzyme in ureagenesis in hepatocytes. ${ }^{151}$ Thus, hepatic ureagenesis would be impaired among alcoholic patients even without severe hepatocyte dysfunction or portosystemic shunting. Muscle loss in this situation may be a result of combined effect of ethanol and ammonia on skeletal muscle. ${ }^{152,153}$ While primary organs for ethanol metabolism are liver and brain, it is known that it can also be metabolized in the skeletal muscle. ${ }^{133,154}$ It indicates a direct effect of ethanol on muscle proteostasis and consequent sarcopenia. ${ }^{155}$ Ethanol feeding in animal models leads to impaired protein synthesis. ${ }^{145,156}$ Human patients with stable alcoholic cirrhosis show impaired protein synthesis in the post-absorptive and post-prandial phases suggesting a state of "anabolic resistance."156,157 The ubiquitin proteasome pathway, is either unaltered or decreased in alcoholic liver disease, while skeletal muscle autophagy is increased and contributes significantly to loss of muscle. Autophagy is a normal cellular adaptive response to eliminate damaged organelles and cytotoxic cellular proteins, but with ethanol consumption, unregulated autophagy adds to muscle loss. Several reports suggest that mammalian target of rapamycin complex 1 (mTORC1) is inhibited by ethanol or its metabolite, acetaldehyde. ${ }^{156,158}$ In addition to stimulating protein synthesis, mTORC1 also suppresses autophagy. ${ }^{159}$ Ethanol has exactly opposite effects via Akt/PKB1 and AMPK, that are upstream regulators of mTORC1. ${ }^{160}$ Overall, evidence shows that ethanol and/or its metabolites cause metabolic, biochemical, and molecular perturbations in the skeletal muscle, with consequent impaired proteostasis. ${ }^{161}$

\section{Endocrine Abnormalities}

Cirrhosis is associated with a number of abnormalities such as low testosterone due to increased aromatase activity. ${ }^{162}$ If the etiology of cirrhosis is ethanol, latter has a direct effect on testicular function. ${ }^{163}$ Similarly, decreased growth hormone concentrations and response in the muscle also contribute to sarcopenia in cirrhosis. ${ }^{164,165}$ Both growth hormone and testosterone are known to inhibit myostatin expression and signaling responses ${ }^{166,167}$ and it is presumed that deficiency of these hormones in cirrhosis also contribute to the impaired protein synthesis and increased myostatin expression. A recent randomized trial showed that testosterone supplementation in male cirrhotics did result in an increase in lean body mass. ${ }^{168}$ Clinical studies have not yet shown any consistent benefit of giving growth hormone to patients with cirrhosis. ${ }^{161}$

\section{Altered Intestinal Function}

Cirrhosis is associated with alterations in gut microbiome and loss of epithelial cell tight junctions that lead to increase in circulating cytokines and 
lipopolysaccharides. ${ }^{12,169}$ Hepatocellular and immune dysfunction as well as portosystemic shunting worsen the endotoxemia due to impaired gut barrier function. ${ }^{170}$ Endotoxemia via tumor necrosis factor (TNF) a dependent and TNF independent pathways may also lead to increased protein breakdown via autophagy and reduced synthesis. ${ }^{171,172}$ Sarcopenic obesity, as seen in patients with NAFLD and after liver transplantation ${ }^{173}$ is also associated with altered gut microbiome. It is possible that the combination of skeletal muscle loss and increased fat mass may contribute to the development of metabolic components including insulin resistance, diabetes mellitus, hyperlipidemia and possibly NAFLD but whether there is a common underlying mechanism for both sarcopenia and obesity is still not known. ${ }^{174}$

\section{Physical Activity}

Physical activity is an important determinant of muscle anabolism and it goes without saying that most patients with cirrhosis, especially those on the transplant waiting lists are sedentary. ${ }^{175}$ Wherever studies are planned to assess the benefit of exercise in such patients, compliance by patients remains very poor. ${ }^{176}$ Those who manage to adhere to the exercise regimen recommended, show a trend toward improved body composition. The best type of exercise for these patients has not been defined, particularly for post-transplant patients. Resistance exercises have been shown to increase muscle protein synthesis in Cirrhosis patients. ${ }^{177}$ Exercise works via stimulating mTORC1 pathway via IGF1 and promotes protein synthesis in muscles (Figure 3).

\section{THERAPEUTIC IMPLICATIONS OF NUTRITION AND SARCOPENIA IN CIRRHOSIS}

Several recent reviews have focused on management strategies for sarcopenia in cirrhosis. ${ }^{161,168}$ Understanding the pathogenesis of malnutrition and sarcopenia in cirrhosis gives us an clear idea about the possible therapeutic strategies one can adopt to reverse these changes (steps 1-7 in Figure 3). Studies in patients with cirrhosis who under went TIPS procedure, and improved their muscle mass have shown marked improved survival probability. ${ }^{84}$

\section{Lifestyle Changes}

\section{Abstinence}

In patients with alcoholic cirrhosis ethanol, it has been shown that alcohol leads to anabolic resistance by suppressing mTORC1 activity. ${ }^{145,158,178}$ As long as the patient continues drinking, progression of liver disease as well as malnutrition and sarcopenia is likely to worsen. That makes abstinence as is foremost therapeutic strategy in such patients. Apart from clinical counseling, cognitive therapy supported by pharmacological measures to promote abstinence is of utmost importance in these patients. ${ }^{179,180}$

\section{Diet}

Several strategies can be adopted to provide extra calories and proteins to these patients such as high-calorie feeding, frequent meals, late evening snack, increasing protein intake and additional of branch chain amino acids in diet. A high-energy, high-protein diet can improve nitrogen retention. ${ }^{181}$ A single strategy may not suffice and a combination of them may succeed in reversing the anabolic resistance seen in cirrhotic patients. ${ }^{182}$

Increasing calorie intake: Patients with cirrhosis have disinclination to eat and are in a state of accelerated starvation, therefore there is need to be force feed either through naso-gastric tube or parenterally in very sick patients. A total of $35-40 \mathrm{kcal} / \mathrm{kg}$ intake per day as per lean body mass is recommended. This approach, though logical, has shown mixed results in various studies. While survival advantage has not been shown in studies on alcoholic cirrhosis, improvement in nitrogen retention and an increase in lean body mass has been reported. ${ }^{182-}$ ${ }^{-184}$ An improvement in directly measured quantification of skeletal muscle mass by image analysis is still awaited.

High protein intake and branch chain amino acids: Protein restriction is no more a recommended strategy and at least $1.5 \mathrm{~g} / \mathrm{kg} / \mathrm{d}$ of protein intake has been recommended by the ESPEN unless contraindicated by a clinical complication. ${ }^{185}$ Vegetable proteins are rich in BCAA which are better utilized by the muscles, and may even have a beneficial effect by removing one mole of ammonia per mole of BCAA. ${ }^{138}$ Preparation of BCAA have been used in the past as treatment for hepatic encephalopathy. ${ }^{186}$ A recent review indicated improvement in hepatic encephalopathy with BCAA but no significant improvement in survival, quality of life or nutritional parameters was reported. ${ }^{187}$ Latter observation was a surprise as BCAA provide a source of energy to the muscle in addition to being substrates for protein synthesis. BCAA also inhibit amino acid deficiency sensor GCN2 and reverse eIF2a phosphorylation which impairs protein synthesis and thereby, improves muscle mass. Leucine is known to activate mTORC1 and facilitate protein synthesis one hand and inhibit autophagy. ${ }^{188}$ These actions are likely to have a cumulative effects that may improve muscle mass. It is possible that the duration of study was not long enough to show these changes. Another study has however shown that a leucine enriched BCAA diet was able to reverse the molecular perturbations in the skeletal muscle downstream of myostatin in cirrhotic patients. ${ }^{145}$ Animal proteins can also be given but are not ideal as they are rich in aromatic amino acids which are not metabolized by the skeletal muscle and may 
worsen encephalopathy. ${ }^{189,190}$ It may be prudent to recommend a third of the protein intake in the form of dairy protein (casein), a third from plant sources (rich in branched chain amino acids) and a third from animal protein (high quality) in compensated cirrhosis. ${ }^{191}$

Frequent meals and late evening snack: In view of accelerated starvation state seen in cirrhosis, overnight fast in cirrhosis has been equated with $72 \mathrm{~h}$ of fasting in healthy individuals. Therefore, frequent meals and late evening snack are recommended to reduce the impact of the fasting. Daytime and nocturnal feeding with the use of late-evening snacks containing a high protein content has been shown to be most beneficial in increasing lean body mass. ${ }^{122}$ This should be combined with early morning breakfast with a complex carbohydrate and protein snack ${ }^{192}$ though this latter recommendation has not been scientifically studied as well as the late evening snack.

Other micronutrients: Zinc levels have been reported to be low among patients with cirrhosis and they seem to affect taste. ${ }^{128}$ Zinc supplements have been shown to improve clinical outcomes in cirrhosis. ${ }^{193}$ Deficiency of fat soluble vitamins such as vitamin D is not uncommon among cirrhosis patients. ${ }^{194}$ Deficiency of vitamin D enhances bone loss in cirrhosis, and its supplementation is expected to be beneficial. These deficiencies may be particularly important in cholestatic diseases, where impaired absorption compounds impaired hepatic hydroxylation, and consequent worsening of defects in calcium homeostasis.

\section{Exercise and Physical Activity}

Frailty and reconditioning in cirrhosis are directly related to contractile muscle dysfunction and fatigue responses. ${ }^{195}$ Physical exercise and incremental activity are known to improve functional performance though its effect on skeletal muscle mass is less well studied. ${ }^{196}$ Type of exercise is important as resistance exercise will increase muscle mass, and endurance exercises will increase functional capacity of muscles and combination of both is likely to be more beneficial. ${ }^{197} \mathrm{~A}$ randomized pilot study used a 6-minute walk test in those who combined daily leucine supplementations with an hour-long treadmill and cycle exercise 3 times a week to achieve 60$70 \%$ maximum heart rate. ${ }^{198}$ Seventeen patients with cirrhosis were randomized to a treatment arm consisting of 12 weeks of exercise, and remaining served as controls. By 24-weeks, patients who exercised had a significant increase in thigh muscle circumference and in overall weight. Plasma ammonia levels decreased in both groups. Similarly, many other reports also indicate consistent improvement in short term outcomes following exercise however its impact on long-term survival, quality of life, and prevention of complications of cirrhosis are not yet known. ${ }^{199}$ Since exercise also increases skeletal muscle ammonia-genesis, cirrhotics with impaired hepatic ammonia clearance capability may have muted benefits. ${ }^{200}$ A recent report indicated that hyperammonemia impairs skeletal muscle strength and increases muscle fatigue on repetitive contraction. ${ }^{201}$ On the other hand, exercise improves skeletal muscle mTORC1 signaling that facilitates muscle anabolism. ${ }^{202}$ When cirrhotic patients are encouraged to exercise, the limitation of this therapy in the face of existing muscle dysfunction must be realized before setting targets. Patients may be advised to walk 30$40 \mathrm{~min}$ three to four times per week if they can, and also lift light hand weights two to three times per week. ${ }^{33}$

\section{Anabolic Hormones}

Cirrhosis is associated with low testosterone and growth hormone secretion compounded with impaired end-organ responses to these hormones. ${ }^{203,204}$ One study ${ }^{205}$ used testosterone gel in 12 hypogonadal men with cirrhosis and showed increased average hand grip strength from $34.03+7.24 \mathrm{~kg}$ to $39.18+5.99 \mathrm{~kg}(P<0.001)$, however, there was no control group. Some other studies have not found it significantly beneficial and also reported several adverse effects. ${ }^{206}$ Since increased peripheral aromatase activity seen in cirrhosis converts testosterone to estradiol, ${ }^{162}$ an aromatase-resistant analog oxandrolone has also been tried, but adverse effects limit its routine use to treat sarcopenia in cirrhosis. ${ }^{161,207}$ Growth hormone that acts through insulin-like growth factor- 1 and promotes mTORC1 signaling in the muscles of cirrhotic patients, has so far not shown adequate benefit in clinical studies. One study has reported that despite adverse effects such as worsening edema and ascites, rhGH could overcame hepatic GH resistance; could improved wholebody protein catabolism; but also increased lipolysis and lipid oxidation; increased insulin resistance; and had potent antinatriuretic effects. ${ }^{208}$ However, evidence is not enough to recommend hormone treatment in cirrhosis to improve muscle mass because of lack of consistent benefit and the potential for significant adverse effects (Table 3). ${ }^{161}$

\section{Ammonia-Lowering Measures}

Hyperammonemia of cirrhosis has emerged as a major contributor of muscle catabolism in cirrhosis and has been found to impair protein synthesis and increase proteolysis by autophagy. ${ }^{134,137,209}$ Ammonia lowering measures including lactulose and rifaximin, which are presently used to treat hepatic encephalopathy, are exciting option to reverse sarcopenia. ${ }^{210}$ Hypothetically Rifaximin may downregulate myostatin levels by reducing serum ammonia and may also release more BCAAs for use as muscle fuel. ${ }^{33}$ Apart from the two methods noted above, another option is use of cell-permeable $\alpha$ keto 
Table 3 A Typical Prescription to Improve Nutrition in Patients with Cirrhosis. Therapies Marked with * are not Recommended for Routine Use but may be Tried in Context of Controlled Trials.

\begin{tabular}{l} 
1. Abstinence from alcohol (take psycho-social and psychiatric help if required) \\
2. Diet \\
1.2-1.5 g of protein per kg of body weight per day (a third from dairy, vegetable protein and animal protein each). Total 35-40 kcal/kg \\
intake per day \\
Suggest late evening snack and early breakfast consisting of complex carbohydrates and protein \\
Supplement branched chain amino acids \\
Use tube feeding (overnight continuous drip) or parenteral nutrition in critically ill patients \\
Zinc, vitamin D and other micronutrient deficiency to be corrected \\
3. Exercise regime consisting of resistance and aerobic exercised, gently increased in a graded manner as per patient's capacity \\
4. Normalization of porta pressure, nonselective beta-blockers or TIPS as indicated \\
5. Ammonia lowering measures \\
Rifaxamine, laculose, aKG, BCAA \\
6. Hormonal therapy \\
Testosterone, oxandrolone, growth hormone* \\
7. Innovative therapies \\
IGF-1, myostatin inhibitors, follostatin, antioxidants, DRP1 inhibitors* \\
8. Liver transplantation* \\
\hline
\end{tabular}

glutarate, which can increase non-hepatic ammonia disposal in the muscle. Other anaplerotic substrates include BCAA isoleucine, which has been shown to be beneficial in lowering ammonia concentrations in preclinical studies. $^{211}$ So far there are no published study to show the impact of these therapies on prevention or reversal of sarcopenia.

\section{Reduction in Portal Pressure}

As has been noted above, an uncontrolled study with TIPSS led to an increase in muscle mass and improvement in prognosis. It also showed an improvement in psoas muscle area by $70 \%$ of patients with an increase in the mean muscle area from $22.8 \mathrm{~cm}^{2}$ at baseline to $25.1 \mathrm{~cm}^{2}$ after TIPSS insertion $(P<0.001) .{ }^{84}$ Possibly several factors other than reduction in portal pressure could have contributed to improvement such as reduced ascites, reduced metabolic rate, increased appetite and improved nutrition. TIPS has also been shown to increases adiponectin production, suggesting an anabolic state. ${ }^{212}$ A welldesigned randomized controlled trial is needed to prove this point.

\section{Newer Targeted Therapies}

As has been mentioned above, main molecular facilitator of protein synthesis is mTORC1, which is counter balanced by myostatin; hence use of myostatin antagonists and mTORC1 activators, have great potential to reverse sarcopenia in cirrhosis. A recent phase 2 proof of concept study in frail older patients ${ }^{213}$ found that a humanised monoclonal anti-myostatin antibody increases APLM [+0.43 kg (CI 0.19-0.66) on active treatment, $P<0.001]$ as well as increases gait speed $(+0.05 \mathrm{~m} / \mathrm{s}, P=0.088)$. So far there are no human trials in cirrhotics. Follistatin, a myostatin antagonist, has proven in animal studies to improve skeletal muscle mass but is yet to be used for patients with cirrhosis-related sarcopenia. ${ }^{214}$ Using a rat model of sarcopenia with a portocaval anastomosis, phenylalanine was used to quantify the fractional and absolute protein synthesis rates in skeletal muscle. ${ }^{215}$ Similarly, in cirrhotic rats, IGF-1 has been shown to improve nitrogen retention, reduce myostatin and increase muscle mass, however, humans studies are lacking. ${ }^{216,217}$ Several new myostatin inhibitors are now being recognized and more than one industry is interested in building muscles. One is likely to see exciting new findings in this area soon. ${ }^{218-220}$ Additional options for new research include using antioxidants, and mitochondrial protective agents, including DRP1 inhibitors, which may hold promise in reversing the molecular abnormalities underlying sarcopenia in cirrhosis. $^{138}$

\section{Liver Transplantation}

Liver transplantation is the main definitive treatment for end stage liver disease and removes several contributors to pathogenesis of sarcopenia. It restores normal hepatocyte function, cures ascites and reduces portal pressure. On the flip side, patient has to take immunosuppressive medications such as corticosteroids, calcineurin inhibitors and mTOR inhibitors which are known to adversely affect muscle mass by activating myokines and also increase fat mass (sarcopenic obesity). Studies have shown that muscle mass can stabilize, increase or decrease after liver transplantation. ${ }^{99,221}$ Some patients may develop 
sarcopenia after liver transplantation. Use of low dose immunosuppresive therapy may be an option, but real task is to develop immunosuppressive therapies that do not adversely affect muscle-signaling responses. Posttransplant obesity is partly related to excessive caloric intake, hence a dietary plan with adequate protein and caloric intake is recommended to avoid obesity, insulin resistance, and sarcopenic obesity. ${ }^{222}$

\section{SUMMARY}

Malnutrition and sarcopenia is commonly seen in patients with cirrhosis and all such patients should undergo a baseline nutritional assessment repeated at regular intervals. Presence of malnutrition and sarcopenia is known to negatively impact survival, quality of life, and response to stressors, such as infection and surgery in patients with cirrhosis. Hand grip testing and L3-SMI are simple, objective and practical methods to assess sarcopenia. Ammonia, poor nutrition, lack of activity, testosterone, and growth hormone are common modifiable factors contributing to sarcopenia and therapy can be planned around them. Optimal energy intake recommended is $35-40 \mathrm{kcal} / \mathrm{kg} /$ day with daily protein intake: $1.2-1.5 \mathrm{~g} / \mathrm{kg},(0.6-0.8 \mathrm{~g} / \mathrm{kg}$ if acute encephalopathy). Small frequent meals evenly distributed through the day and a bedtime snack of complex carbohydrates and protein can minimize muscle loss. Branchedchain amino acid supplementation may help achieve daily protein goals in patients who are protein intolerant. Enteral feeds through a nasoenteral tube are indicated in patients who cannot reach caloric intake goals with oral supplements; parenteral feeds are reserved for patients who cannot reach caloric intake goals by oral or enteral routes and are critically ill. Ammonia lowering strategies, anabolic steroids, increased physical activity, reducing portal pressure and myostatin inhibitors are other approaches that can hold potential. Liver transplantation may not necessarily correct sarcopenia of chronic liver disease.

\section{CONFLICTS OF INTEREST}

The author has none to declare.

\section{ACKNOWLEDGEMENT}

The author is indebted to Dr. Srinivas Dasarathy, Gastroenterologist and Hepatologist, Cleveland Clinic Main Campus, Cleveland, OH44195 USA for his help and guidance in preparing this manuscript.

\section{REFERENCES}

1. Merli M, Giusto M, Gianneli V, Lucidi C, Reggio O. Nutritional status and liver transplantation. J Clin Exp Hepatol. 2011;1:190-198.

2. WHO Online Q\&A. What is Malnutrition. At http://www.who.int/ features/qa/malnutrition/en/ (08.07.16).
3. Periyalwar P, Dasarathy S. Malnutrition in cirrhosis: contribution and consequences of sarcopenia on metabolic and clinical responses. Clin Liver Dis. 2012;16:95-131.

4. Montano-Loza AJ, Meza-Junco J, Prado CM, et al. Muscle wasting is associated with mortality in patients with cirrhosis. Clin Gastroenterol Hepatol. 2011;10:166-173.

5. Pugh RN, Murray-Lyon IM, Dawson JL, Pietroni MC, Williams R. Transection of the oesophagus for bleeding oesophageal varices. Br J Surg. 1973;60:646-649.

6. D'Amico G, Garcia-Tsao G, Pagliaro L. Natural history and prognostic indicators of survival in cirrhosis: a systematic review of 118 studies. J Hepatol. 2006;44:217-231.

7. Kamath PS, Kim WR. The model for end-stage liver disease (MELD). Hepatology. 2007;45:797-805.

8. Johnson TM, Overgard EB, Cohen AE, DiBaise JK. Nutrition assessment and management in advanced liver disease. Nutr Clin Pract. 2013;28:15-29.

9. Montano-Loza AJ, Angulo P, Meza-Junco J, et al. Sarcopenic obesity and myosteatosis are associated with higher mortality in patients with cirrhosis. J Cachexia Sarcopenia Muscle. 2016;7(2):126-135.

10. Petersen KF, Befroy D, Dufour S, et al. Mitochondrial dysfunction in the elderly: possible role in insulin resistance. Science. 2003;300:1140-1142.

11. Kim TN, Park MS, Lim KI, et al. Relationships between sarcopenic obesity and insulin resistance, inflammation, and vitamin D status: the Korean Sarcopenic Obesity Study. Clin Endocrinol. 2013;78:525-532.

12. Ferreira LG, Martins AIF, Cunha CE, Anastácio LR, Lima AS, Correia MI. Negative energy balance secondary to inadequate dietary intake of patients on the waiting list for liver transplantation. Nutrition. 2013;29:1252-1258.

13. Periyalwar P, Dasarathy S. Malnutrition in cirrhosis: contribution and consequences of sarcopenia on metabolic and clinical responses. Clin Liver Dis. 2012;16(1):95-131.

14. Chinn KS. Prediction of muscle and remaining tissue protein in man. J Appl Physiol. 1967;23(5):713-715.

15. Krzywicki HJ, Chinn KS. Body composition of a military population, Fort Carson, 1963. I. Body density, fat, and potassium 40. Am J Clin Nutr. 1967;20(7):708-715.

16. Argiles JM, Anker SD, Evans WJ, et al. Consensus on cachexia definitions. J Am Med Dir Assoc. 2010;11(4):229-230.

17. Cederholm T, Barazzoni R, Austin P, et al. ESPEN guidelines on definitions and terminology of clinical nutrition. Clin Nutr. 2017;36:149-164.

18. Dasarathy S. Consilience in sarcopenia of cirrhosis. $J$ Cachexia Sarcopenia Muscle. 2012;3:225-237.

19. Cruz-Jentoft AJ, Baeyens JP, Bauer JM, et al. Sarcopenia: European consensus on definition and diagnosis: report of the European Working Group on Sarcopenia in Older People. Age Ageing. 2010;39(4):412-423.

20. Romiti A, Merli M, Martorano M, et al. Malabsorption and nutritional abnormalities in patients with liver cirrhosis. Ital J Gastroenterol. 1990;22:118-123.

21. Cederholm T, Bosaeus I, Barazzoni R, et al. Diagnostic criteria for malnutrition e an ESPEN consensus statement. Clin Nutr. 2015;34:335-340.

22. White JV, Guenter P, Jensen G, Malone A, Schofield M. Consensus statement: Academy of Nutrition and Dietetics and American Society for Parenteral and Enteral Nutrition: characteristics recommended for the identification and documentation of adult malnutrition (undernutrition). JPEN $J$ Parenter Enter Nutr. 2012;36:275-283.

23. Muscaritoli M, Anker SD, Argilés J, et al. Consensus definition of sarcopenia, cachexia and pre-cachexia: joint document elaborated by Special Interest Groups (SIG) "cachexia-anorexia in 
chronic wasting diseases" and "nutrition in geriatrics". Clin Nutr. 2010;29:154-159.

24. Fielding RA, Vellas B, Evans WJ, et al. Sarcopenia: an undiagnosed condition in older adults. Current consensus definition: prevalence, etiology, and consequences. International working group on sarcopenia. J Am Med Dir Assoc. 2011;12:249-256.

25. Landi F, Calvani R, Cesari M, et al. Sarcopenia as the biological substrate of physical frailty. Clin Geriatr Med. 2015;31:367374.

26. Fried LP, Tangen CM, Walston J, et al. Frailty in older adults: evidence for a phenotype. J Gerontol A Biol Sci Med Sci. 2001;56:M146-M156.

27. Stenholm S, Harris TB, Rantanen T, Visser M, Kritchevsky SB, Ferrucci L. Sarcopenic obesity: definition, cause and consequences. Curr Opin Clin Nutr Metab Care. 2008;11:693-700.

28. Jeejeebhoy KN, Keller H, Gramlich L, et al. Nutritional assessment: comparison of clinical assessment and objective variables for the prediction of length of hospital stay and readmission. Am J Clin Nutr. 2015;101:956-965.

29. Madden AM, Smith S. Body composition and morphological assessment of nutritional status in adults: a review of anthropometric variables. J Hum Nutr Diet. 2016;29(1):7-25.

30. Prado CM, Birdsell LA, Baracos VE. The emerging role of computerized tomography in assessing cancer cachexia. Curr Opin Support Palliat Care. 2009;3:269-275.

31. Masuda T, Shirabe K, Ikegami T, et al. Sarcopenia is a prognostic factor in living donor liver transplantation. Liver Transpl. 2014;20:401-407.

32. Shen W, Punyanitya M, Wang ZM, et al. Total body skeletal muscle and adipose tissue volumes: estimation from a single abdominal cross-sectional image. J Appl Physiol. 2004; 97:2333-2338.

33. Sinclair M, Gow PJ, Grossmann M, et al. Review article: sarcopenia in cirrhosis-aetiology, implications and potential therapeutic interventions. Aliment Pharmacol Ther. 2016;43:765777.

34. Bauer JM, Verlaan S, Bautmans I, et al. Effects of a vitamin D and leucine-enriched whey protein nutritional supplement on measures of sarcopenia in older adults, the PROVIDE study: a randomized, double-blind, placebo-controlled trial. J Am Med Dir Assoc. 2015;16:740-747.

35. Guralnik JM, Simonsick EM, Ferrucci L, et al. A short physical performance battery assessing lower extremity function: association with self-reported disability and prediction of mortality and nursing home admission. J Gerontol. 1994;49:M85-M94.

36. de Morton NA, Davidson M, Keating JL. Validity, responsiveness and the minimal clinically important difference for the de Morton Mobility Index (DEMMI) in an older acute medical population. BMC Geriatr. 2010;10:72. http://dx.doi.org/10.1186/ 1471-2318-10-72.

37. Colin C, Wade DT, Davies S, Horne V. The Barthel ADL index. A reliability study. Int Disabil Stud. 1988;10:61-63.

38. McCullough AJ, Buglianesi E. Protein calorie malnutrition and the etiology of cirrhosis. Am J Gastroenterol. 1997;92:734738.

39. Nutritional status in cirrhosis. Italian Multicentre Cooperative Project on Nutrition in Liver Cirrhosis. J Hepatol. 1997;21:317325.

40. Thuluvath PJ, Triger DR. How valid are our reference standards of nutrition? Nutrition. 1995;11(6):731-733.

41. Thuluvath PJ, Triger DR. Evaluation of nutritional status by using anthropometry in adults with alcoholic and nonalcoholic liver disease. Am J Clin Nutr. 1994;60(2):269-273.

42. Mendenhall CL, Anderson S, Weesner RE, et al. Protein-calorie malnutrition associated with alcoholic hepatitis. Veterans
Administration Cooperative Study Group on Alcoholic Hepatitis. Am J Med. 1984;76(2):211-222.

43. DiCecco SR, Wieners EJ, Wiesner RH, et al. Assessment of nutritional status of patients with end-stage liver disease undergoing liver transplantation. Mayo Clin Proc. 1989;64 (1):95-102.

44. Lautz HU, Selberg O, Korber J, et al. Protein-calorie malnutrition in liver cirrhosis. Clin Investig. 1992;70(6):478-486.

45. Caregaro L, Alberino F, Amodio P, et al. Malnutrition in alcoholic and virus-related cirrhosis. Am J Clin Nutr. 1996;63:602-609.

46. Hehir DJ, Jenkins RL, Bistrian BR, Blackburn GL. Nutrition in patients undergoing orthotopic liver transplant. J Parenter Enteral Nutr. 1985;9:695-700.

47. Charlton MR. Alcoholic liver disease: energy and protein metabolism in alcoholic liver disease. Clin Liver Disease J. 1998;2:781-798.

48. Cheung K, Lee SS, Raman M. Prevalence and mechanisms of malnutrition in patients with advanced liver disease, and nutrition management strategies. Clin Gastroenterol Hepatol. 2012;10:117-125.

49. Akerman PA, Jenkins RL, Bistrian BR. Preoperative nutrition assessment in liver transplantation. Nutrition. 1993;9(4):350356.

50. Morgan MY, Madden AM. The assessment of body composition in patients with cirrhosis. Eur J Nucl Med. 1996;23(2):213225.

51. Loguercio C, Sava E, Sicolo P, et al. Nutritional status and survival of patients with liver cirrhosis: anthropometric evaluation. Minerva Gastroenterol Dietol. 1996;42(2):57-60.

52. Reisman Y, Gips CH, Lavelle SM. Assessment of liver cirrhosis severity in 1015 patients of the Euricterus database with Campbell-Child. Pugh-Child and with ascites and ascites-nutritional state (ANS) related classifications. Euricterus Project Management Group. Hepatogastroenterology. 1997;44 (17):1376-1384.

53. Roongpisuthipong C, Sobhonslidsuk A, Nantiruj K, et al. Nutritional assessment in various stages of liver cirrhosis. Nutrition. 2001;17(9):761-765.

54. Alberino F, Gatta A, Amodio P, et al. Nutrition and survival in patients with liver cirrhosis. Nutrition. 2001;17(6):445-450.

55. Lehnert ME, Clarke DD, Gibbons JG, et al. Estimation of body water compartments in cirrhosis by multiple-frequency bioelectrical-impedance analysis. Nutrition. 2001;17(1):31-34.

56. Caly WR, Strauss E, Carrilho FJ, et al. Different degrees of malnutrition and immunological alterations according to the aetiology of cirrhosis: a prospective and sequential study. Nutr J. 2003;2:10. Available at https://nutritionj.biomedcentral. com/articles/10.1186/1475-2891-2-10 Accessed 31.08.17.

57. Figueiredo FA, De Mello PR, Kondo M. Effect of liver cirrhosis on body composition: evidence of significant depletion even in mild disease. J Gastroenterol Hepatol. 2005;20(2):209-216.

58. Alvares-da-Silva MR, da Reverbel ST. Comparison between handgrip strength, subjective global assessment, and prognostic nutritional index in assessing malnutrition and predicting clinical outcome in cirrhotic outpatients. Nutrition. 2005;21 (2):113-117.

59. Peng S, Plank LD, McCall JL, et al. Body composition, muscle function, and energy expenditure in patients with liver cirrhosis: a comprehensive study. Am J Clin Nutr. 2007;85(5):12571266.

60. Sam J, Nguyen GC. Protein-calorie malnutrition as a prognostic indicator of mortality among patients hospitalized with cirrhosis and portal hypertension. Liver Int. 2009;29(9):1396-1402.

61. de Carvalho L, Parise ER, Samuel D. Factors associated with nutritional status in liver transplant patients who survived the 
first year after transplantation. J Gastroenterol Hepatol. 2010;25(2):391-396.

62. Muller MJ, Böttcher J, Selberg O, et al. Hypermetabolism in clinically stable patients with liver cirrhosis. Am J Clin Nutr. 1999;69:1194-1201.

63. O'Keefe SJ, El-Zayadi AR, Carraher TE, Davis M, Williams R. Malnutrition and immuno-incompetence in patients with liver disease. Lancet. 1980;2:615-617.

64. Marsano L, McClain CJ. Nutrition and alcoholic liver disease. J Parenter Enteral Nutr. 1991;15:337-344.

65. Pikul J, Sharpe MD, Lowndes R, Ghent CN. Degree of preoperative malnutrition is predictive of postoperative morbidity and mortality in liver transplant recipients. Transplantation. 1994;57:469-472.

66. Kim HY, Jang JW. Sarcopenia in the prognosis of cirrhosis: going beyond the MELD score. World J Gastroenterol. 2015;21:7637-7647.

67. Figueiredo FA, Perez RM, Freitas MM, et al. Comparison of three methods of nutritional assessment in liver cirrhosis: subjective global assessment, traditional nutritional parameters, and body composition analysis. J Gastroenterol. 2006;41 (5):476-482.

68. Durand F, Valla D. Assessment of the prognosis of cirrhosis: Child-Pugh versus MELD. J Hepatol. 2005;42(suppl 1):S100S107.

69. Moctezuma-Velazquez C, García-Juárez I, Soto-Solís R, Hernández-Cortés J, Torre A. Nutritional assessment and treatment of patients with liver cirrhosis. Nutrition. 2013;29:1279-1285.

70. Thandassery RB, Montano-Loza AJ. Role of nutrition and muscle in cirrhosis. Curr Treat Options Gastro. 2016;14:257-273.

71. Rantanen T, Harris T, Leveille SG, et al. Muscle strength and body mass index as long-term predictors of mortality in initially healthy men. J Gerontol A Biol Sci Med Sci. 2000;55(3):M168M173.

72. Norman K, Kirchner H, Lochs H, Pirlich M. Malnutrition affects quality of life in gastroenterology patients. World J Gastroenterol. 2006;12:3380-3385.

73. Merli M, Giusto M, Lucidi C, et al. Muscle depletion increases the risk of overt and minimal hepatic encephalopathy: results of a prospective study. Metab Brain Dis. 2013;28(2):281-284.

74. Kalaitzakis E, Olsson R, Henfridsson P, et al. Malnutrition and diabetes mellitus are related to hepatic encephalopathy in patients with liver cirrhosis. Liver Int. 2007;27(9):1194-1201.

75. Huisman EJ, Trip EJ, Siersema PD, et al. Protein energy malnutrition predicts complications in liver cirrhosis. Eur J Gastroenterol Hepatol. 2011;23(11):982-989.

76. Carey EJ, Steidley DE, Aqel BA, et al. Six-minute walk distance predicts mortality in liver transplant candidates. Liver Transpl. 2010;16:1373-1378.

77. Lai JC, Feng S, Terrault N, et al. Frailty predicts waitlist mortality in liver transplant candidates. Am J Transpl. 2014;14(8):18701879.

78. Merli M, Riggio O, Dally L. Does malnutrition affect survival in cirrhosis? Hepatology. 1996;23:1041-1046.

79. Montano-Loza AJ, Meza-Junco J, Prado CM, et al. Muscle wasting is associated with mortality in patients with cirrhosis. Clin Gastroenterol Hepatol. 2012;10(2):166-173. 173.e1.

80. Hanai T, Shiraki M, Nishimura K, et al. Sarcopenia impairs prognosis of patients with liver cirrhosis. Nutrition. 2015;31 (1):193-199.

81. Hamaguchi Y, Kaido T, Okumura S, et al. Impact of quality as well as quantity of skeletal muscle on outcomes after liver transplantation. Liver Transpl. 2014;20:1413-1419.

82. Durand F, Buyse S, Francoz C, et al. Prognostic value of muscle atrophy in cirrhosis using psoas muscle thickness on computed tomography. J Hepatol. 2014;60(6):1151-1157.
83. van Vugt JL, Levolger S, de Bruin RW, et al. Systematic review and meta-analysis of the impact of computed tomography assessed skeletal muscle mass on outcome in patients awaiting or undergoing liver transplantation. Am J Transpl. 2016;16:2277-2292.

84. Tsien C, Shah SN, McCullough AJ, Dasarathy S. Reversal of sarcopenia predicts survival after a transjugular intrahepatic portosystemic stent. Eur J Gastro Hepatol. 2013;25:85-93.

85. Cosqueric G, Sebag A, Ducolombier C, Thomas C, Piette F, Weill-Engerer $\mathrm{S}$. Sarcopenia is predictive of nosocomial infection in care of the elderly. Br J Nutr. 2006;96:895-901.

86. Fernandez J, Acevedo J, Castro M, et al. Prevalence and risk factors of infections by multiresistant bacteria in cirrhosis: a prospective study. Hepatology. 2012;55:1551-1561.

87. Harrison J, McKiernan J, Neuberger JM. A prospective study on the effect of recipient nutritional status on outcome in liver transplantation. Transpl Int. 1997;10:369-374.

88. Krell RW, Kaul DR, Martin AR, et al. Association between sarcopenia and the risk of serious infection among adults undergoing liver transplantation. Liver Transpl. 2013;19:1396-1402.

89. Kalyani RR, Corriere M, Ferrucci L. Age-related and diseaserelated muscle loss: the effect of diabetes, obesity, and other diseases. Lancet Diabetes Endocrinol. 2014;2:819-829.

90. D'Souza R, Sabin CA, Foster GR. Insulin resistance plays a significant role in liver fibrosis in chronic hepatitis $C$ and in the response to antiviral therapy. Am J Gastroenterol. 2005;100:1509-1515.

91. Hung $\mathrm{CH}$, Wang $\mathrm{JH}$, Hu TH, et al. Insulin resistance is associated with hepatocellular carcinoma in chronic hepatitis $\mathrm{C}$ infection. World J Gastroenterol. 2010;16:2265-2271.

92. Pedersen BK, Febbraio MA. Muscles, exercise and obesity: skeletal muscle as a secretory organ. Nat Rev Endocrinol. 2012;8:457-465.

93. Marchesini G, Bianchi G, Amodio P, et al. Factors associated with poor health-related quality of life of patients with cirrhosis. Gastroenterology. 2001;120:170-178.

94. Mehta SS, Fallon MB. Muscle cramps in liver disease. Clin Gastroenterol Hepatol. 2013;11:1385-1391. quiz e80.

95. DiMartini A, Cruz Jr RJ, Dew MA, et al. Muscle mass predicts outcomes following liver transplantation. Liver Transpl. 2013;19:1172-1180.

96. Merli M, Giusto M, Gentili F, et al. Nutritional status: its influence on the outcome of patients undergoing liver transplantation. Liver Int. 2010;30(2):208-214.

97. Stephenson G, Moretti E, El-Moalem H, et al. Malnutrition in liver transplant patients: preoperative subjective global assessment is predictive of outcome after liver transplantation. Transplantation. 2001;72(4):666-670.

98. Englesbe MJ, Patel SP, He K, et al. Sarcopenia and mortality after liver transplantation. J Am Coll Surg. 2010;211:271-278.

99. Tsien C, Garber A, Narayanan A, et al. Post-liver transplantation sarcopenia in cirrhosis: a prospective evaluation. J Gastroenterol Hepatol. 2014;29:1250-1257.

100. Dasarathy S. Posttransplant sarcopenia: an underrecognized early consequence of liver transplantation. Dig Dis Sci. 2013;58:3103-3111.

101. Riggio O, Andreoli A, Diana F, et al. Whole body and regional body composition analysis by dual-energy X-ray absorptiometry in cirrhotic patients. Eur J Clin Nutr. 1997;51:810-814.

102. Kallwitz ER. Sarcopenia and liver transplant: the relevance of too little muscle mass. World J Gastroenterol. 2015;21 (39):10982-10993.

103. Hanai T, Shiraki M, Ohnishi S, et al. Rapid skeletal muscle wasting predicts worse survival in patients with liver cirrhosis. Hepatol Res. 2016;46(8):743-751. 
104. Plauth M, Schutz ET. Cachexia in liver cirrhosis. Int J Cardiol. 2002;85:83-87.

105. Izbeki F, Kiss I, Wittmann T, Varkonyi TT, Legrady P, Lonovics J. Impaired accommodation of proximal stomach in patients with alcoholic liver cirrhosis. Scand J Gastroenterol. 2002;37:14031410.

106. Aqel BA, Scolapio JS, Dickson RC, Burton DD, Bouras EP. Contribution of ascites to impaired gastric function and nutritional intake in patients with cirrhosis and ascites. Clin Gastroenterol Hepatol. 2005;3:1095-1100.

107. Gunnarsdottir SA, Sadik R, Shev S, et al. Small intestinal motility disturbances and bacterial overgrowth in patients with liver cirrhosis and portal hypertension. Am J Gastroenterol. 2003;98:1362-1370.

108. Kalaitzakis E, Simren M, Olsson R, et al. Gastrointestinal symptoms in patients with liver cirrhosis: associations with nutritional status and health-related quality of life. Scand J Gastroenterol. 2006;41:1464-1472.

109. Tsiaousi ET1. Hatzitolios AI, Trygonis SK, Savopoulos CG. Malnutrition in end stage liver disease: recommendations and nutritional support. J Gastroenterol Hepatol. 2008;23 (4):527-533.

110. Moscatiello S, Manini R, Marchesini G. Diabetes and liver disease: an ominous association. Nutr Metab Cardiovas. 2007;17:63-70.

111. Müller MJ, Lautz HU, Plogmann B, Bürger M, Körber J, Schmidt FW. Energy expenditure and substrate oxidation in patients with cirrhosis: the impact of cause, clinical staging and nutritional state. Hepatology. 1992;15:782-794.

112. Wiest R, Lawson M, Geuking M. Pathological bacterial translocation in liver cirrhosis. J Hepatol. 2014;60:197-209.

113. Mathur S, Peng S, Gane EJ, McCall JL, Plank LD. Hyper-metabolism predicts reduced transplant-free survival independent of MELD and Child-Pugh scores in liver cirrhosis. Nutrition. 2007;23:398-403.

114. Selberg O, Böttcher J, Tusch G, Pichlmayr R, Henkel E, Müller MJ. Identification of high- and low-risk patients before liver transplantation: a prospective cohort study of nutritional and metabolic parameters in 150 patients. Hepatology. 1997;25:652-657.

115. Wasmuth HE, Kunz D, Yagmur E, et al. Patients with acute on chronic liver failure display 'sepsis-like' immune paralysis. J Hepatol. 2005;42:195-201.

116. Iwasaki A, Medzhitov R. Control of adaptive immunity by the innate immune system. Nat Immunol. 2015;16:343-353.

117. Hernaez R, Solà E, Moreau R, Ginès P. Acute-on-chronic liver failure: an update. Gut. 2017;66:541-553.

118. Glass C, Hipskind P, Tsien C, et al. Sarcopenia and a physiologically low respiratory quotient in patients with cirrhosis: a prospective controlled study. J Appl Physiol. 2013;114:559565.

119. Crawford $D$. Recent advances in malnutrition and liver disease. J Gastroenterol. 1995;48:1-4.

120. Shanbhogue RL, Bistrian BR, Jenkins RL, et al. Resting energy expenditure in patients with end-stage liver disease and in normal population. J Parenter Enteral Nutr. 1987;11:305-308.

121. Peng S, Plank LD, McCall JL, Gillanders LK, Mcllroy K, Gane EJ. Body composition, muscle function, and energy expenditure in patients with liver cirrhosis: a comprehensive study. Am J Clin Nutr. 2007;85:1257-1266.

122. Tsien CD, McCullough AJ, Dasarathy S. Late evening snack: exploiting a period of anabolic opportunity in cirrhosis. J Gastroenterol Hepatol. 2012;27:430-441.

123. Sarin SK, Dhingra N, Bansal A, Malhotra S, Guptan RC. Dietary and nutritional abnormalities in alcoholic liver disease: a comparison with chronic alcoholics without liver disease. Am J Gastroenterol. 1997;92:777-783.

124. Rode A, Fourlanos S, Nicoll A. Oral vitamin D replacement is effective in chronic liver disease. Gastroenterol Clin Biol. 2010;34(11):618-620.

125. Crawford BA, Labio ED, Strasser SI, et al. Vitamin D replacement for cirrhosis-related bone disease. Nat Clin Pract Gastroenterol Hepatol. 2006;3(12):689-699.

126. Bavdekar A, Bhave S, Pandit A. Nutrition management in chronic liver disease. Indian J Pediatr. 2002;69(5):427-431.

127. Madden AM, Bradbury W, Morgan MY. Taste perception in cirrhosis: its relationship to circulating micronutrients and food preferences. Hepatology. 1997;26:40-48.

128. Stamoulis I, Kouraklis G, Theocharis S. Zinc and the liver: an active interaction. Dig Dis Sci. 2007;52(7):1595-1612.

129. Prado CM, Wells JC, Smith SR, Stephan BC, Siervo M. Sarcopenic obesity: a critical appraisal of the current evidence. Clin Nutr. 2012;31:583-601.

130. Kob R, Bollheimer LC, Bertsch T, et al. Sarcopenic obesity: molecular clues to a better understanding of its pathogenesis? Biogerontology. 2015;16:15-29.

131. Biolo G, Cederholm T, Muscaritoli M. Muscle contractile and metabolic dysfunction is common feature of sarcopenia of aging and chronic diseases: from sarcopenic obesity to cachexia. Clin Nutr. 2014;33:737-748.

132. Egerman MA, Glass DJ. Signaling pathways controlling skeletal muscle mass. Crit Rev Biochem Mol Biol. 2014;49:59-68.

133. Thapaliya S, Runkana A, McMullen MR, et al. Alcohol-induced autophagy contributes to loss in skeletal muscle mass. Autophagy. 2014;10:677-690.

134. Qiu J, Tsien C, Thapalaya S, et al. Hyperammonemia-mediated autophagy in skeletal muscle contributes to sarcopenia of cirrhosis. Am J Physiol Endocrinol Metab. 2012;303:E983E993.

135. Ganda OP, Ruderman NB. Muscle nitrogen metabolism in chronic hepatic insufficiency. Metabolism. 1976;25:427-435.

136. Shangraw RE, Jahoor F. Effect of liver disease and transplantation on urea synthesis in humans: relationship to acid-base status. Am J Physiol. 1999;276:G1145-G1152.

137. Qiu J, Thapaliya S, Runkana A, et al. Hyperammonemia in cirrhosis induces transcriptional regulation of myostatin by an NF-kappaB-mediated mechanism. Proc Natl Acad Sci U S A. 2013:110:18162-18167.

138. Dasarathy S, Merli M. Sarcopenia from mechanism to diagnosis and treatment in liver disease. J Hepatol. 2016;65:12321244.

139. Garcia PS, Cabbabe A, Kambadur R, Nicholas G, Csete M. Briefreports: elevated myostatin levels in patients with liver disease: a potential contributor to skeletal muscle wasting. Anesth Analg. 2010;111:707-709.

140. Merli M, Giusto M, Molfino A, et al. MuRF-1 and p-GSK3beta expression in muscle atrophy of cirrhosis. Liver Int 2013:33:714-721.

141. Han HQ, Zhou X, Mitch WE, Goldberg AL. Myostatin/activin pathway antagonism: molecular basis and therapeutic potential. Int J Biochem Cell Biol. 2013;45:2333-2347.

142. Kosenko E, Venediktova N, Kaminsky Y, Montoliu C, Felipo V. Sources of oxygen radicals in brain in acute ammonia intoxication in vivo. Brain Res. 2003;981:193-200.

143. Davuluri G, Krokowski D, Guan BJ, et al. Metabolic adaptation of skeletal muscle to hyperammonemia drives the beneficia effects of L-leucine in cirrhosis. J Hepatol. 2016;65:929-937.

144. Owen OE, Kalhan SC, Hanson RW. The key role of anaplerosis and cataplerosis for citric acid cycle function. $J$ Biol Chem. 2002;277:30409-30412. 
145. Tsien C, Davuluri G, Singh D, et al. Metabolic and molecular responses to leucine-enriched branched chain amino acid supplementation in the skeletal muscle of alcoholic cirrhosis. Hepatology. 2015;61:2018-2029.

146. Breuillard C, Cynober L, Moinard C. Citrulline and nitrogen homeostasis: an overview. Amino Acids. 2015;47:685-691.

147. Glass C, Hipskind P, Cole D, Lopez R, Dasarathy S. Handheld calorimeter is a valid instrument to quantify resting energy expenditure in hospitalized cirrhotic patients: a prospective study. Nutr Clin Pract. 2012;27:677-688.

148. Owen OE, Reichle FA, Mozzoli MA, et al. Hepatic, gut, and renal substrate flux rates in patients with hepatic cirrhosis. J Clin Invest. 1981;68:240-252.

149. Landau BR, Schumann WC, Chandramouli V, Magnusson I, Kumaran K, Wahren J. 14C-labeled propionate metabolism in vivo and estimates of hepatic gluconeogenesis relative to Krebs cycle flux. Am J Physiol. 1993;265:E636-E647.

150. Bonet-Ponce L, Saez-Atienzar S, da Casa C, et al. On the mechanism underlying ethanol-induced mitochondrial dynamic disruption and autophagy response. Biochim Biophys Acta. 2015;1852:1400-1409.

151. Holmuhamedov EL, Czerny C, Beeson CC, Lemasters JJ. Ethanol suppresses ureagenesis in rat hepatocytes: role of acetaldehyde. J Biol Chem. 2012;287:7692-7700.

152. Mendenhall CL, Tosch T, Weesner RE, et al. VA cooperative study on alcoholic hepatitis. II. Prognostic significance of protein-calorie malnutrition. Am J Clin Nutr. 1986;43:213-218.

153. Nutritional status in cirrhosis. Italian Multicentre Cooperative Project on Nutrition in Liver Cirrhosis. J Hepatol. 1994;21:317325.

154. Estonius M, Danielsson O, Karlsson C, Persson H, Jornvall H, Hoog JO. Distribution of alcohol and sorbitol dehydrogenases. Assessment of mRNA species in mammalian tissues. Eur J Biochem. 1993;215:497-503.

155. Uppal R, Rosman A, Hernandez R, Baraona E, Lieber CS. Effects of liver disease on red blood cell acetaldehyde in alcoholics and non-alcoholics. Alcohol Alcohol. (suppl 1):1991;(suppl 1):323-326.

156. Steiner JL, Lang $\mathrm{CH}$. Alcohol impairs skeletal muscle protein synthesis and mTOR signaling in a time-dependent manner following electrically stimulated muscle contraction. J App/ Physiol (1985). 2014;117:1170-1179.

157. Sneddon AA, Koll M, Wallace MC, et al. Acute alcohol administration inhibits the refeeding response after starvation in rat skeletal muscle. Am J Physiol Endocrinol Metab. 2003;284: E874-E882.

158. Lang CH, Frost RA, Deshpande N, et al. Alcohol impairs leucinemediated phosphorylation of 4E-BP1, S6K1, elF4G, and mTOR in skeletal muscle. Am J Physiol Endocrinol Metab. 2003;285: E1205-E1215.

159. Laplante M, Sabatini DM. mTOR signaling in growth control and disease. Cell. 2012;149:274-293.

160. Korzick DH, Sharda DR, Pruznak AM, Lang CH. Aging accentuates alcohol-induced decrease in protein synthesis in gastrocnemius. Am J Physiol. 2013;304(10):R887-R898. http:// dx.doi.org/10.1152/ajpregu.00083.2013.

161. Dasarathy J, McCullough AJ, Dasarathy S. Sarcopenia in alcoholic liver disease: clinical and molecular advances. Alcohol Clin Exp Res. 2017;41(8):1419-1431. http://dx.doi.org/ 10.1111/acer.13425 [Epub 11.08.17].

162. Dasarathy S, Mullen KD, Dodig M, Donofrio B, McCullough AJ. Inhibition of aromatase improves nutritional status following portacaval anastomosis in male rats. $J$ Hepatol. 2006;45:214220.

163. Villalta J, Ballesca JL, Nicolas JM, Martinez de Osaba MJ, Antunez E, Pimentel C. Testicular function in asymptomatic chronic alcoholics: relation to ethanol intake. Alcohol Clin Exp Res. 1997;21:128-133.

164. Bucuvalas JC, Cutfield W, Horn J, et al. Resistance to the growthpromoting and metabolic effects of growth hormone in children with chronic liver disease. J Pediatr. 1990;117:397-402.

165. Moller S, Becker U, Gronbaek M, Juul A, Winkler K, Skakkebaek NE. Short-term effect of recombinant human growth hormone in patients with alcoholic cirrhosis. J Hepatol. 1994;21:710-717.

166. Liu W, Thomas SG, Asa SL, Gonzalez-Cadavid N, Bhasin S, Ezzat S. Myostatin is a skeletal muscle target of growth hormone anabolic action. J Clin Endocrinol Metab. 2003;88:5490-5496.

167. Lakshman KM, Bhasin S, Corcoran C, et al. Measurement of myostatin concentrations in human serum: circulating concentrations in young and older men and effects of testosterone administration. Mol Cell Endocrinol. 2009;302:26-32.

168. Sinclair M, Grossmann M, Hoermann R, Angus PW, Gow PJ. Testosterone therapy increases muscle mass in men with cirrhosis and low testosterone: a randomised controlled trial. J Hepatol. 2016;65:906-913.

169. Engen PA, Green SJ, Voigt RM, Forsyth CB, Keshavarzian A. The gastrointestinal microbiome: alcohol effects on the composition of intestinal microbiota. Alcohol Res. 2015;37:223-236.

170. Bajaj JS, Heuman DM, Hylemon PB, et al. Altered profile of human gut microbiome is associated with cirrhosis and its complications. J Hepatol. 2014;60:940-947.

171. Keller CW, Fokken C, Turville SG, et al. TNF-alpha induces macroautophagy and regulates MHC class II expression in human skeletal muscle cells. J Biol Chem. 2011;286:3970-3980.

172. Lang $\mathrm{CH}$, Frost RA, Nairn AC, MacLean DA, Vary TC. TNF-alpha impairs heart and skeletal muscle protein synthesis by altering translation initiation. Am J Physiol Endocrinol Metab. 2002;282:E336-E347.

173. Carias S, Castellanos AL, Vilchez V, et al. Nonalcoholic steatohepatitis is strongly associated with sarcopenic obesity in patients with cirrhosis undergoing liver transplant evaluation. $J$ Gastroenterol Hepatol. 2016;31:628-633.

174. Merli M, lebba V, Giusto M. What is new about diet in hepatic encephalopathy. Metab Brain Dis. 2016;31(6):1289-1294.

175. Kallwitz ER, Loy V, Mettu P, Von Roenn N, Berkes J, Cotler SJ. Physical activity and metabolic syndrome in liver transplant 68 recipients. Liver Transpl. 2013;19:1125-1131.

176. Krasnoff JB, Vintro AQ, Ascher NL, et al. A randomized trial of exercise and dietary counseling after liver transplantation. Am J Transpl. 2006;6:1896-1905.

177. Hasten DL, Pak-Loduca J, Obert KA, Yarasheski KE. Resistance exercise acutely increases MHC and mixed muscle protein synthesis rates in 78-84 and 23-32 years olds. Am J Physiol Endocrinol Metab. 2000;278:E620-E626.

178. Hong-Brown LQ, Brown CR, Kazi AA, Navaratnarajah M, Lang $\mathrm{CH}$. Rag GTPases and AMPK/TSC2/Rheb mediate the differential regulation of mTORC1 signaling in response to alcohol and leucine. Am J Physiol Cell Physiol. 2012;302:C1557-C1565.

179. Lee MR, Leggio L. Combined pharmacotherapies for the management of alcoholism: rationale and evidence to date. CNS Drugs. 2014;28:107-119.

180. Miller PG, Curtis A, Sonderlund A, Day A, Droste N. Effectiveness of interventions for convicted DUI offenders in reducing recidivism: a systematic review of the peer-reviewed scientific literature. Am J Drug Alcohol Abuse. 2015;41:16-29.

181. Dichi JB, Dichi I, Maio R, et al. Whole-body protein turnover in malnourished patients with child class $B$ and $C$ cirrhosis on diets low to high in protein energy. Nutrition. 2001;17:239242.

182. Fialla AD, Israelsen M, Hamberg O, Krag A, Gluud LL. Nutritional therapy in cirrhosis or alcoholic hepatitis: a systematic review and meta-analysis. Liver Int. 2015;35:2072-2078. 
183. Puri P, Thursz M. Intensive enteral nutrition in alcoholic hepatitis: more food for thought. Gastroenterology. 2016;150:803-805.

184. Moreno C, Deltenre P, Senterre C, et al. Intensive enteral nutrition is ineffective for patients with severe alcoholic hepatitis treated with corticosteroids. Gastroenterology. 2016;150:903910. e908.

185. Plauth M, Cabre E, Riggio O, et al. ESPEN guidelines on enteral nutrition: liver disease. Clin Nutr. 2006;25:285-294.

186. Metcalfe EL, Avenell A, Fraser A. Branched-chain amino acid supplementation in adults with cirrhosis and porto-systemic encephalopathy: systematic review. Clin Nutr. 2014;33:958965.

187. Gluud LL, Dam G, Les I, et al. Branched-chain amino acids for people with hepatic encephalopathy. Cochrane Database Syst Rev. 2015;9:CD001939.

188. Carroll B, Korolchuk VI, Sarkar S. Amino acids and autophagy: cross-talk and co-operation to control cellular homeostasis. Amino Acids. 2015;47:2065-2088.

189. Bembr A, Bembr A. The amino acid composition of animal tissue protein. J Biol Chem. 1943.

190. Nguyen DL, Morgan T. Protein restriction in hepatic encephalopathy is appropriate for selected patients: a point of view. Hepatol Int. 2014;8:447-451.

191. Dasarathy S. Nutrition and alcoholic liver disease: effects of alcoholism on nutrition, effects of nutrition on alcoholic liver disease, and nutritional therapies for alcoholic liver disease. Clin Liver Dis. 2016;20:535-550.

192. Vaisman N, Katzman H, Carmiel-Haggai M, Lusthaus M, Niv E. Breakfast improves cognitive function in cirrhotic patients with cognitive impairment. Am J Clin Nutr. 2010;92:137-140.

193. Matsuoka S, Matsumura H, Nakamura H, et al. Zinc supplementation improves the outcome of chronic hepatitis $\mathrm{C}$ and liver cirrhosis. J Clin Biochem Nutr. 2009;45(3):292-303.

194. Konstantakis C, Tselekouni P, Kalafateli M, Triantos C. Vitamin D deficiency in patients with liver cirrhosis. Ann Gastroenterol. 2016;29(3):297-306.

195. Tapper EB, Finkelstein D, Mittleman MA, Piatkowski G, Lai M. Standard assessments of frailty are validated predictors of mortality in hospitalized patients with cirrhosis. Hepatology. 2015;62:584-590.

196. Toshikuni N, Arisawa T, Tsutsumi M. Nutrition and exercise in the management of liver cirrhosis. World I Gastroenterol. 2014;20(23):7286-7297.

197. Damas F, Phillips S, Vechin FC, et al. A review of resistance training-induced changes in skeletal muscle protein synthesis and their contribution to hypertrophy. Sports Med. 2015;45:801807.

198. Román E, Torrades MT, Nadal MJ, et al. Randomized pilot study: effects of an exercise programme and leucine supplementation in patients with cirrhosis. Dig Dis Sci. 2014;59(8):1966-1975.

199. Toshikuni N, Arisawa T, Tsutsumi M. Nutrition and exercise in the management of liver cirrhosis. World I Gastroenterol. 2014;20(23):7286-7297. http://dx.doi.org/10.3748/wjg. v20.i23.7286.

200. Sahlin K, Tonkonogi M, Söderlund K. Plasma hypoxanthine and ammonia in humans during prolonged exercise. Eur J Appl Physiol Occup Physiol. 1999;80:417-422.

201. McDaniel J, Davuluri G, Hill EA, et al. Hyperammonemia results in reduced muscle function independent of muscle mass. $A m \mathrm{~J}$ Physiol. 2016;310(3):G163-G170. http://dx.doi.org/ 10.1152/ajpgi.00322.2015.

202. Hornberger TA, Chu WK, Mak YW, Hsiung JW, Huang SA, Chien $\mathrm{S}$. The role of phospholipase $\mathrm{D}$ and phosphatidic acid in the mechanical activation of mTOR signaling in skeletal muscle. Proc Natl Acad Sci U S A. 2006;103(12):4741-4746.
203. Sinclair M, Grossmann M, Gow PJ, Angus PW. Testosterone in men with advanced liver disease: abnormalities and implications. J Gastroenterol Hepatol. 2015;30:244-251.

204. Baruch Y, Assy N, Amit T, et al. Spontaneous pulsatility and pharmacokinetics of growth hormone in liver cirrhotic patients. J Hepatol. 1998;29:559-564.

205. Yurci A, Yucesoy M, Unluhizarci K, et al. Effects of testosterone gel treatment in hypogonadal men with liver cirrhosis. Clin Res Hepatol Gastroenterol. 2011;35:845-854.

206. Gluud G. Testosterone treatment of men with alcoholic cirrhosis: a double-blind study. Hepatology. 1986;6:807-813.

207. Orr R, Fiatarone Singh M. The anabolic androgenic steroid oxandrolone in the treatment of wasting and catabolic disorders: review of efficacy and safety. Drugs. 2004;64:725-750.

208. Wallace JD, Abbott-Johnson WJ, Crawford DH, Barnard R, Potter JM, Cuneo RC. GH treatment in adults with chronic liver disease: a randomized, double-blind, placebo-controlled, crossover study. J Clin Endocrinol Metab. 2002;87(6):2751-2759.

209. Holecek M, Sprongl L, Tichý M. Effect of hyperammonemia on leucine and protein metabolism in rats. Metabolism. 2000;49:1330-1334.

210. Rose CF. Ammonia-lowering strategies for the treatment of hepatic encephalopathy. Clin Pharmacol Ther. 2000;92:321331.

211. Dam G, Ott P, Aagaard NK, Vilstrup H. Branched-chain amino acids and muscle ammonia detoxification in cirrhosis. Metab Brain Dis. 2013;28:217-220.

212. Thomsen KL, Sandahl TD, Holland-Fischer P, et al. Changes in adipokines after transjugular intrahepatic porto-systemic shunt indicate an anabolic shift in metabolism. Clin Nutr. 2012;31 (6):940-945.

213. Becker C, Lord SR, Studenski SA, et al. Myostatin antibody (LY2495655) in older weak fallers: a proof-of-concept, randomised, phase 2 trial. Lancet Diabetes Endocrinol. 2015;3:948957.

214. Lucero C, Verna EC. The role of sarcopenia and frailty in hepatic encephalopathy management. Clin Liver Dis. 2015;19:507528.

215. Dasarathy S, McCullough AJ, Muc S, et al. Sarcopenia associated with portosystemic shunting is reversed by follistatin. $J$ Hepatol. 2011;54(5):915-921.

216. Lang CH, Frost RA, Svanberg E, Vary TC. IGF-I/IGFBP-3 ameliorates alterations in protein synthesis, elF4E availability, and myostatin in alcohol-fed rats. Am J Physiol Endocrinol Metab. 2004;286:E916-E926.

217. Picardi A, de Oliveira AC, Muguerza B, et al. Low doses of insulin-like growth factor-l improve nitrogen retention and food efficiency in rats with early cirrhosis. J Hepatol. 1997;26:191202.

218. Yang CL, Luo AL. Myokines: a promising therapeutic target for hepatic encephalopathy. J Hepatol. 2017;66:1099-1100.

219. Fan $H$, Zhang R, Tesfaye D, et al. Sulforaphane causes a major epigenetic repression of myostatin in porcine satellite cells. Epigenetics. 2012;7(12):1379-1390.

220. Smith RC, Lin BK. Myostatin inhibitors as therapies for muscle wasting associated with cancer and other disorders. Curr Opin Support Palliat Care. 2013;7:352-360.

221. Bergerson JT, Lee JG, Furlan A, et al. Liver transplantation arrests and reverses muscle wasting. Clin Transpl. 2015;29:216-221.

222. Pagadala M, Dasarathy S, Eghtesad B, McCullough AJ. Posttransplant metabolic syndrome: an epidemic waiting to happen. Liver Transpl. 2009;15:1662-1670. 